\title{
Cortical-limbic mechanisms and response control: A theoretical review
}

\author{
ROBERT NUMAN \\ University of Santa Clara, Santa Clara, California 95053
}

\begin{abstract}
The literature dealing with the behavioral effects produced by lesions of the septum, frontal cortical areas, and the hippocampus is reviewed. It is concluded that the dorsomedial septum, the dorsolateral frontal cortex (and homologous structures), and the dorsal hippocampus form a nodal point within a larger neuronal system that is involved in response regulation. A model describing the response regulatory processes mediated by this frontal cortical-limbic system is proposed. Motor programs are written in frontal cortex and temporarily stored in hippocampus. Feedback stimuli derived from response initiation and maintenance are compared against the stored hippocampal motor program. If the feedback information matches with the expected outcomes dictated by the motor program, the response sequence is terminated. If comparator deviations arise, the frontal cortical areas are signaled of error and a new motor program is written. Hippocampal theta activity is postulated to be a correlate of comparator activation and feedback analysis.
\end{abstract}

The present review is advanced in an attempt to integrate a large body of data dealing with frontocortical and limbic mechanisms, especially as they relate to response regulatory functions. The aim has been, throughout, to bring divergent lines of evidence together in order to build a model of response control. The review, therefore, is theoretical and, at times, speculative.

While the review is not exhaustive, the research cited is representative of current findings. Reference to numerous review articles has been included to guide interested readers to more comprehensive discussions of particular details. In attempting to build a model of response regulation, emphasis has been placed on anatomical findings, and the behavioral effects of brain damage (lesions, ablations) in animals. Electrophysiological and neurochemical data are included when clearly relevant.

I have decided not to include research dealing with aversive paradigms in this review. A comment seems necessary on this point. While avoidance and punishment paradigms are clearly important, and may relate, at least in part, to the current thesis, I chose to exclude these data for a number of reasons. (1) This literature has recently been reviewed (Black, Nadel, \& O'Keefe, 1977; Caplan, 1973). (2) While there is good anatomical specificity for the effects of limbic lesions on response regulation in appetitive paradigms, such anatomical specificity is lacking in some aversive paradigms (Clody \& Carlton, 1969;

Requests for reprints should be sent to Robert Numan, Department of Psychology, University of Santa Clara, Santa Clara, California 95053. The author would like to thank Shirley Robinson for her excellent assistance in typing this manuscript.
Hamilton, Kelsey, \& Grossman, 1970; Kelsey, 1976; Kelsey \& Grossman, 1975; MacDougall \& Capobianco, 1976). Further, where anatomical conclusions can be drawn, the data support the view of an anatomical dissociation between neural regions mediating response regulation and those mediating avoidance learning (Clody \& Carlton, 1969; Donovick, 1968; Hamilton et al., 1970; Ross \& Grossman, 1975, 1977; Ross, Grossman, \& Grossman, 1975). Since the major emphasis in this review is on response regulation, we will, accordingly, focus on the neural regions mediating this process. (3) Lastly, since large limbic lesions may modify both emotionality and response regulation, paradigms employing aversive stimuli may confound these factors, making evaluation of the data difficult.

A word of caution at the outset. The proposed model should not be construed as characterizing a unitary function for cortical and limbic mechanisms. Frontal cortex and limbic system subserve many functions, including motivation, emotion, and memory, as well as response regulation. While there is some degree of anatomical specificity for these functions, a great deal of functional overlap and interaction probably also occurs. Therefore, in stressing response regulatory functions, anatomically precise statements will be attempted. Further, where possible, dissociation (or integration, if the data so indicates) of response regulatory mechanisms from motivational, emotional, and mnemonic mechanisms will be attempted.

The neural regions emphasized in this review include the septum, hippocampus, and frontal association cortex. It is my contention that specific portions of these structures and their connections 
form a nodal point within a larger neuronal system that is involved in the programming and regulation of response patterns.

This corticofrontal-limbic system is conceived to include the following: (1) the programming of spatially and temporally integrated sequential movements, (2) the calibration of motor programs based on response produced feedback information, and (3) differential stimulation of motor and sensory mechanisms (e.g., modified postural orientation and differential attention) for the efficient reception of anticipated meaningful stimulus input.

In the following section, the importance of sensory feedback for the programming and regulation of response patterns will be discussed, stressing the interaction between peripheral and central mechanisms. In the two succeeding sections, the anatomy of two neural regions, namely the septum and frontal lobes, will be outlined. An understanding of these neural relations strongly suggests that these structures are part of the central mechanisms involved in response control and sensory-motor integration. The conclusions formulated in these two neuroanatomical sections will be reinforced by a selective review of the behavioral effects produced by destruction of these neural regions. I follow with a selective discussion of the hippocampus, which appears to be an important structural and functional link between frontal and limbic mechanisms. Finally, a neurobehavioral model of response regulatory mechanisms will be formulated. It should be noted that when terms like "motor acts," "motor program," and "response control" are used, I am referring to the more molar aspects of efference (i.e., behavioral acts) rather than the movement of individual muscle groups.

\section{FEEDBACK AND RESPONSE CONTROL}

Feedback may be simply defined as the stimulus consequences of behavior. Feedback, therefore, is information gained through responding (or not responding). Within the framework of this definition, one can readily distinguish at least two types of feedback information: (1) feedback derived from the external environment, and (2) feedback derived from the organism's own responses. These divisions can be further subdivided (e.g., see Greenwald, 1970; Taub, Teodoru, Ellman, Bloom, \& Berman, Note 1), but this will not be necessary for our purposes.

Early models of behavioral control through feedback mechanisms were developed by James (1890) and von Holst (1954). More recent endeavors (Adams, 1968; Anokhin, 1969; Greenwald, 1970; Kimble \& Perlmuter, 1970) stress the same basic concepts, but have modified certain terminological and theoretical positions. The more recent models have also questioned whether or not feedback mechanisms are con- trolled by peripheral-central loops, strictly central loops, or, for that matter, whether feedback is necessary at all for response control (Evarts, 1971). Before we take a closer look at this problem, a brief description of the role played by feedback mechanisms in response control, general to most theories, will be undertaken.

Generally, motor programs are believed to be "written" in the cerebral cortex. The programming of these motor acts is probably determined by the sum total of sensory information available to the organism (internal and external), the organism's emotional and motivational state of arousal, and previous experiential factors (memories). The sum total of these factors is analyzed in the cerebral cortex, and the initial stages of behavioral programming are set into motion. Motor programs are "written" in terms of expected outcomes which are based on the organism's intent. The activation of a motor program leads to the formation of an efference copy (corollary discharge, acceptor of action) of that program in the central nervous system. While the motor program is being carried out, reafference [proprioceptive, interoceptive, or exteroceptive feedback which is response dependent; reafference should be contrasted with exafference which refers to responseindependent stimulus changes (von Holst, 1954)] is compared against the efference copy. Comparator deviations give rise to response modifications until the expected outcomes are attained, matching feedback with the efference copy. The response sequence is then terminated (see Anokhin, 1969, and Evarts, 1971 , for a more detailed discussion.)

During this century, one type of feedback information, proprioceptive feedback, has received a great deal of attention and has led to many controversies. A selective survey of these efforts will be important to us since most of the findings have indicated that peripheral and central factors interact to form an integrative system for response control.

The initial emphasis on the importance of proprioceptive feedback in motor control was derived from the work of Sherrington at the turn of the century. Mott and Sherrington (cited in Taub \& Berman, 1968) found that unilateral limb deafferentation led to loss of "purposeful" use of the involved limb in monkeys.

Similar conclusions were derived from the early studies of Small (1900) and Watson (1907) in their discussion of maze learning in rats. These investigators found that rats with damage to sensory modalities such as vision and audition could still learn a maze task. They concluded that such efficient performance was due to proprioceptive factors. Controversy soon developed, and more rigorous experimentation was conducted. Finally, the results indicated that while proprioception may be utilized in 
maze learning, it is not a necessary form of feedback information, feedback from other modalities or even central mechanisms alone being sufficient (Adams, 1968).

The work of Taub and his associates (Taub \& Berman, 1968; Taub et al., Note 1; Taub \& Berman, Note 2) has helped to clarify this matter. These investigators have performed both partial and complete unilateral and bilateral rhizotomy in monkeys. Furthermore, in many cases, the monkeys were blindfolded to omit the use of visual cues. After surgical manipulation, free-ranging activity and retention and acquisition of conditioned avoidance tasks were studied. The surgical procedures did not seem to affect the final behavioral level of competence of the animals. Based on these findings, Taub has proposed that: "once a motor program has been written into the CNS (by whatever means), the specified behavior, having been initiated, can be performed without any guidance from extrinsic sources"' (Taub et al., Note 1, page 12).

However, though Taub found that the final level of competence on these tasks was similar for normal and deafferented monkeys, he also found that deafferentation severely retarded the acquisition of an avoidance response by a factor of three (Taub, Teodoru, Ellman, Bloom \& Berman, 1966) and increased resistance to extinction of an avoidance response by a factor of four (Taub et al., Note 1). In addition, "deafferents" showed an initial deficit in retention of an avoidance response (Taub \& Berman, Note 2). Finally, Taub (Taub et al., 1966) found that if additional feedback (experimenter produced) was afforded the deafferented monkeys during extinction of an avoidance response, they then extinguished normally.

Such results would indicate that in the normal animal motor programs are "written" by the nervous system via feedback mechanisms similar to those described previously. These programs compare sensory information derived from movement with the movement command (efference copy). When peripheral feedback into this neural system is disrupted, the CNS becomes dependent mainly upon central mechanisms. This changeover from a peripheralcentral mechanism to a strictly central one may be related to the initial performance decrements noted by Taub.

The investigations of Laszlo (Laszlo, Shamoon, \& Sanson-Fisher, 1969) lend further support for the interaction of central and peripheral factors in movement control. Laszlo found that while the presence of proprioceptive feedback is not essential to performance of skilled motor tasks in humans, her subjects, nonetheless, performed such tasks with reduced efficiency at the beginning of training.

Research involving the effects of prismatic trans- formation of the visual field in humans also supports the position that, in normal organisms, movement feedback plays a strong role in the control and integration of motor activity. Since the investigations of Stratton in the $1800 \mathrm{~s}$, there has developed a large body of literature dealing with the analysis of the mechanisms involved in adaptation to prismatic displacement. Most of these studies (Epstein, 1967; Held, 1968) have indicated that active movement and its consequent proprioceptive feedback are the relevant variables involved in adaptation to prismatic displacement. However, Kornheiser (1976) has more recently contended that active movement is not necessary for adaptation. Nonetheless, he does maintain that adaptation probably involves both peripheral and central components.

In conclusion, then, it appears that movement control is dependent upon the integrity of a neuronal servomechanism under normal conditions, and that a peripheral-central mechanism is probably functionally dominant. However, the plasticity of the CNS seems to allow for central control of movement in the absence of peripheral feedback. Thus, superimposed upon the peripheral-central feedback mechanism, there also appears to be a functionally reliable centrally localized feedback loop for movement control. It is my contention that frontocortical-limbic mechanisms comprise part of the central pathways regulating sensory-motor integration and the programming of motor acts.

\section{THE NEUROANATOMY OF THE SEPTUM AND SEPTOHIPPOCAMPAL RELATIONS}

The septal area consists of a group of nuclei located within the general forebrain area commonly termed the limbic system. This nuclear group lies beneath the corpus callosum in the anteromedial wall of the hemisphere. It extends sagittally as far as the lateral ventricles, is bounded anterodorsally by the genu of the corpus callosum, and caudally by the descending columns of the fornix (Fox, 1940). The major nuclear groups of the septum include the medial and lateral septal nuclei, the posterior septal nucleus, the septofimbrial nucleus, the nucleus triangularis septi, and the nucleus of the diagonal band (Andy \& Stephan, 1968; Fox, 1940; Raisman, 1966).

In the present discussion, I will outline the most important septal connections, paying special attention to septohippocampal relations, especially as they are related to the control of the hippocampal theta rhythm. The efferents of the septum will be discussed first, followed by a discussion of septal afferents.

\section{Septal Efferents}

Septal efferents can be subdivided into diencephalic and telencephalic components. The major projection 
sites of the diencephalic component include the hypothalamus, habenula, perhaps the dorsomedial nucleus of the thalamus, and certain mesencephalic structures. The major projection sites of the telencephalic component are the hippocampus and olfactory tubercle.

Diencephalic projections. Some of the fibers that leave the septum travel dorsally in the stria medullaris to terminate in the habenula. Raisman (1966) presents anatomical support for a septofimbrial origin of these fibers in rat. This is an important pathway, since it is a major link between forebrain structures and extrapyramidal structures of the midbrain. From the habenula, fibers travel in the fasciculus retroflexus to the interpeduncular nucleus, and from there to the tegmental areas of the midbrain (cat material, Nauta, 1958; rat material, Wang \& Aghajanian, 1977). This circuit can be further extended back to forebrain structures via tegmental connections with the mammillary bodies (Krieckhaus, Note 3).

A large group of fibers arise throughout the lateral and medial septal nuclei and travel ventrally in the medial forebrain bundle. These fibers terminate at various levels of the hypothalamus (rat material, Raisman, 1966), and Nauta (1958, cat material) has indicated that some of these fibers or their secondary projections travel as far as the subthalamus and even reach extrapyramidal and reticular structures of the midbrain. Guillery (1959, cat material) and Powell (1966, cat material) have also suggested that the medial septal nucleus and the diagonal band nuclei project to the nucleus medialis dorsalis of the thalamus. This is an important connection, since the mammalian dorsomedial nucleus is connected with the prefrontal cortical areas (Akert, 1964).

Telencephalic component. The most important component of the telencephalic septal projection is to the hippocampus. We will discuss this projection in more detail shortly. For the present, it will suffice to note that, in rat, these fibers arise in the medial septal nucleus and diagonal band nucleus, and project via the fimbria and dorsal fornix to the posteroventral and anterodorsal portion of the hippocampus (Lewis \& Shute, 1967; Raisman, Cowan, \& Powell, 1966). However, in cat, Siegel and Tassoni (1971b) have found that the lateral septum also projects to the hippocampus. They have shown that the medial septum of cat projects to dorsal hippocampus, while the lateral septum projects to ventral hippocampus.

\section{Septal Afferents}

Septal afferents can also be discussed in terms of diencephalic and telencephalic components.

Diencephalic component. The medial forebrain bundle is the major ascending pathway through which diencephalic and mesencephalic fibers reach the septum. Fibers arising in the hypothalamus travel to the lateral septal nucleus, while fibers arising in the mesencephalon travel to the medial septal nucleus (Guillery, 1957, rat material; Nauta, 1958, cat material; Raisman, 1966, rat material).

Telencephalic component. The major telencephalic projection to the septum in rodents and cats arises in the hippocampus and travels in the dorsal fornix and fimbria to all areas of the septum (Nauta, 1958; Raisman, 1966; Raisman et al., 1965, 1966; Siegel, Edinger, \& Ohgami, 1974). In addition, the olfactory tubercle, pyriform cortex, and perhaps amygdala project to the septum (Raisman, 1966).

One anatomical system in the septum is of particular interest because it is probably responsible for the mediation of the hippocampal theta rhythm. Green and Arduini (1954) showed that the theta rhythm is evoked via pathways running from the septum to the hippocampus, and that blockage of the pathway via fornix section or specific septal lesions results in a disruption of the theta rhythm. Neuroanatomically, rostrally projecting fibers arising in the mesencephalon enter the medial forebrain bundle, course through the hypothalamus and preoptic area and ascend to the nucleus of the diagonal band (Guillery, 1957, rat material; Nauta, 1958, cat material). From this point, fibers enter the medial septal nucleus and project to the hippocampus (Lewis \& Shute, 1967, rat material; Raisman, 1966, rat material; Siegel \& Tassoni, 1971b, cat material). In addition, this projection from the medial septum to the hippocampus, at least in rat, is probably a cholinergic pathway (Lewis \& Shute, 1967; Smith, 1974).

Evidence suggests that, in rabbits and rats, fibers from the diagonal band and the portion of medial septum along the midline are responsible for the pacing of the hippocampal theta response (Macadar, Roig, Monti, \& Budelli, 1970; Petsche, Gogolak, \& Van Zwieten, 1965; Petsche, Stumpf, \& Gogolak, 1962). These fibers travel in the dorsal fornix to hippocampal area $\mathrm{CA}_{1}$ and perhaps $\mathrm{CA}_{4}$ (Lewis \& Shute, 1967). In addition, hippocampal area $C_{1}$ projects back upon the medial septum via the dorsal fornix (Raisman et al., 1966). Thus, the possibility exists here for a feedback loop between the medial septum and hippocampal area $\mathrm{CA}_{1}$ for septohippocampal modulation of the theta response. It should be mentioned, however, that Raisman (1966) denies the existence of fibers from the medial septum via the dorsal fornix to hippocampal field $\mathrm{CA}_{1}$. Instead, he emphasizes a projection from the medial septal nucleus by way of the fimbria to fields $\mathrm{CA}_{3}$ and $\mathrm{CA}_{4}$ of the hippocampus. However, these fibers appear to arise in the more lateral portions of the medial septum (Raisman et al., 1965).

Interestingly, a series of recent papers by Siegel and associates (Meibach \& Siegel, 1977; Siegel et al., 1974; Siegel \& Tassoni, 1971a, 1971b) have presented 
convincing evidence that the relationships between hippocampus and septum may actually be organized along the dorsoventral axis of the hippocampus rather than along the cytoarchitectonic subfields of the hippocampus (i.e., $\mathrm{CA}_{1}, \mathrm{CA}_{2}, \mathrm{CA}_{3}, \mathrm{CA}_{4}$ ). According to Siegel's group, the medial septum projects to dorsal hippocampus and receives projections from dorsal hippocampus, while the ventral hippocampus is similarly related to the lateral septal areas. Intermediate regions of the hippocampus along its dorsoventral axis are related to an area intermediate between medial and lateral septum. These projections are independent of cytoarchitectonic subfields. Further, the projection from dorsal hippocampus to medial septum leaves the hippocampus via the dorsal fornix and travels in medial regions of the fornix, while the projection from the ventral hippocampus to the lateral septum leaves the hippocampus via the fimbria and travels in the lateral regions of the fornix. Finally, these results were found to be similar in gerbil, rat, rabbit, and cat. The most recent paper by this group (Meibach \& Siegel, 1977) presents some additional findings of interest. They show that many of the fibers projecting from hippocampus to septum in rats arise in the subicular areas rather than hippocampal pyramidal cells, and that projections from dorsal hippocampal areas terminate in the dorsal portions of the medial septum (dorsomedial quadrant of lateral septal nucleus). Recent neurochemical data support some of Siegel's findings (Olton, Walker, \& Gage, 1978). Further research is needed before the functional aspects of these connections can be determined. At minimum, they indicate a structural relation between lateral septum and ventral hippocampus, on the one hand, and the dorsomedial septum and dorsal hippocampus, on the other. These structural relations may prove to enhance our understanding of functional considerations.

Based on the neuroanatomical connections just discussed, it would appear reasonable to assume that the lateral portions of the septum and perhaps the ventral hippocampus, by way of close association with hypothalamic centers, regulate autonomic processes and emotional behavior in general. The dorsal septum, medial septum, and diagonal band, on the other hand, seem to comprise an important linkage point between the mesencephalic reticular formation, mesencephalic motor centers, and dorsal hippocampus. It is these portions of the septum which I believe to be of importance for response control.

\section{NEUROANATOMY OF FRONTAL CORTICAL AREAS}

All cortex lying rostral to the central fissure (cruciate sulcus of carnivores) is considered frontal cortex. However, frontal cortex has been subdivided cytoarchitectonically into motor, premotor, and nonmotor (association) areas (Akert, 1964). In nonhuman primates, the motor and association areas are separated by the arcuate fissure, the motor areas lying caudal to the arcuate fissure with its caudal boundary being the central fissure. Association cortex is designated as all cortex rostral to the arcuate sulcus. Within the arcuate sulcus itself is located the transitional area 8 of Brodmann, or the frontal eye fields. Histologically, frontal association cortex in primates contains a well-defined cortical layer IV which consists of granular cells (relatively absent in the motor area which has a rich pyramidal layer V), and is topographically related to the dorsomedial nucleus of the thalamus. It is with the nonmotor frontal association cortex that the research to be reviewed herein is concerned.

The frontal association cortex (FAC) of primates is further subdivided into dorsolateral and orbital sectors. In carnivores, the FAC is divided into a proreal and orbital area. The proreal area is inclusive to the gyrus proreus and, based on thalamocortical relations (Akert, 1964), is probably homologous to the dorsolateral division of primates. The location of homologous orbital cortex may lie within the carnivore orbital gyrus, but behavioral studies in dogs (Dabrowska, 1971) suggest a possible location in the medial wall of the frontal pole. In rodents, the whole area of the frontal pole has, until quite recently, been considered FAC. However, a number of recent studies (Hall \& Lindholm, 1974; Krettek \& Price, 1977a; Leonard, 1969) have shown that this is not the case. These investigations have shown that most of the area of the frontal pole, especially laterally, is motor-type cortex. Only cortex lying on the midline and anterior to the corpus callosum is analogous to the dorsolateral sector of the primates. Furthermore, in rodents, an area on the ventral surface of the brain in and around the rhinal sulcus is analogous to the orbital cortex of higher forms. A number of behavioral studies have recently lent support to these findings (Divac, 1971; Kolb, Nonneman, \& Singh, 1974; Nonneman, Voight, \& Kolb, 1974; Numan, Seifert, \& Lubar, 1975).

\section{FAC Relations to the Dorsomedial Nucleus of the Thalamus}

If one were to delineate FAC by cytoarchitectonics alone, it would be difficult to determine if carnivores, rodents, and other subprimate forms do indeed have frontal association cortex that is homologous to that of primates (Akert, 1964; Leonard, 1969). However, the dorsomedial nucleus of the thalamus does project topographically to differential frontal cortical zones in all mammals. Rose and Woolsey (1948) suggested that this cortical projection field of the nucleus medialis dorsalis be considered homo- 
logous FAC, even though interspecific differences in cytoarchitectonics may exist. Most anatomists have followed this suggestion, and the behavioral evidence to be reviewed shortly also supports this position.

The nucleus medialis dorsalis of primates is subdivided into three regions: a medial magnocellular region, a lateral parvocellular region, and an extreme paralamellar region. The magnocellular region projects to the orbital surface, the parvocellular region to the dorsolateral sector, and the paralamellar portion to the transitional area 8 of Brodmann (Akert, 1964; Auer, 1956; Leonard, 1969). Similar relations have been extended to subprimates (Akert, 1964; Krettek \& Price, 1977a; Leonard, 1969).

\section{Corticocortical Connections of FAC}

Recent neuroanatomical (Jones, 1969; Pandya, Hallett, \& Mukherjee, 1969; Pandya \& Kuypers, 1969; Pandya \& Vignolo, 1971) and neurophysiological (Beritashvili, 1971; Bignall \& Imbert, 1969; Encabo \& Ruarte, 1967; Livanov, 1969) investigations have strongly indicated that the FAC of primates and carnivores may be a prime site for the integration and analysis of sensory and motor information. In general, what has been shown is that the somatic, auditory, and visual areas first project to premotor cortex and their surrounding association cortex of origin. From these new secondary sites, fibers are projected again to surrounding areas and further anterior into the FAC. Furthermore, the new projection sites in the FAC are reciprocally interconnected with the original local projection areas of the primary sensory cortex and the supplementary motor areas. Further, it would appear that monkey dorsolateral cortex receives predominantly somatosensory input, while orbital cortex receives predominantly visual and auditory input (Chavis \& Pandya, 1976).

\section{Neuroanatomical Relations Between FAC and Subcortical Centers}

Early interest in FAC centered around psychosurgical techniques. The effects of frontal lobotomy on emotional and social behavior were often attributed to disconnection of the FAC from the hypothalamus (Freeman \& Watts, 1950; Girgis, 1971; Mettler, 1949). Connections from the hypothalamus to the FAC do, in fact, exist. In monkey, afferents to the frontal lobe arise in the posterior hypothalamus, ascend to the magnocellular division of the dorsomedial nucleus of the thalamus, and from there are transmitted to the orbital surface of the FAC (Clark, 1948). Furthermore, the FAC (dorsolateral and orbital sectors) projects back upon the hypothalamus. The sites of termination are in the supraoptic and paraventricular nuclei, the lateral and posterior hypothalamic areas, and the mammillary bodies
(Clark, 1948). More recent studies in monkey (Devito \& Smith, 1964; Johnson, Rosvold, \& Mishkin, 1968) have emphasized hypothalamic terminations in the lateral hypothalamic and lateral preoptic areas. Similar frontal efferents have been found in the cat and rat after frontal ablation (Auer, 1956; Leonard, 1969).

Besides its corticocortical relations with motor and premotor areas of the brain as outlined above, the FAC of primates, carnivores, and rodents has strong neural relations to extrapyramidal subcortical motor centers. Thus, there are efferents from the frontal cortical areas to the head of the caudate nucleus, putamen, claustrum, zona incerta, field $\mathrm{H}$ of Forel, nucleus subthalamicus, substantia nigra, and the nuclei of the midbrain tegmentum (Beritashvili, 1971; Devito \& Smith, 1964; Girgis, 1971; Johnson et al., 1968; Leonard, 1969). Furthermore, the FAC may influence cerebellar mechanisms in primates, carnivores, and rodents via a projection to the pontine nuclei (Brodal, 1971a, 1971b; Devito \& Smith, 1964; Leonard, 1969).

\section{Limbic Relations of FAC}

Nauta (1964) has indicated that, in monkey, the dorsolateral sector of the frontal cortical areas is closely related to the hippocampus, while the orbital surface of the frontal lobes is more closely related to the temporal lobe and amygdala. He points out that fibers leaving the dorsolateral sector diffusely distribute through the cingulum and terminate in juxtahippocampal regions. Secondary fibers arising from this point enter the hippocampus. In further support for a relationship between dorsalateral cortex with hippocampus, Butters and Pandya (1969) found that selective lesions to the middle and anterior portions of sulcus principalis of the dorsolateral frontal surface in monkeys led to degeneration in cingulate gyrus, parahippocampal gyrus, and association cortex of the temporal lobe. All of these areas have access to the hippocampus-ultimately via entorhinal cortex (Iversen, 1976). We should note, however, that while such long fiber connections have been readily demonstrated in monkey material, they have not been demonstrated in rat (Leonard, 1969). On the other hand, the orbital surface, while also sending fibers to entorhinal cortex and hippocampus (Van Hoesen, Pandya, \& Butters, 1972, 1975), is strongly related to the amygdala in monkey, cat, and perhaps rat (Girgis, 1971; Krettek \& Price, 1977b; Nauta, 1964; Valverde,1965). One aspect of these data is clear, the entorhinal cortex seems to be a critical link between frontal association cortex and the limbic system. Van Hoesen et al. (1972) emphasize that the entorhinal cortex "is a final cortical link between the sensory systems of the neocortex and the hippocampus and dentate gyrus of the limbic system." 
The sensory-motor integrations that we have assumed to take place in the frontal cortical areas could further act to modulate the channeling and processing of new sensory information in any one of three ways: (1) via reciprocal projections back to areas of primary sensory input (Jones, 1969), (2) via projections to the medial forebrain bundle, which carries reticular excitation to the limbic system (Mizuno, Clemente, \& Sauerland, 1969; Valverde, 1965 ), and (3) via projections to the midline and intralaminar thalamic nuclear groups which constitute a major thalamic site for the telencephalic projection of the ascending reticular formation (Auer, 1956; Johnson et al., 1968).

Furthermore, it would appear that the FAC sends efferent fibers to the septum. However, the site of origin of these fibers within the FAC is not yet clear. Johnson et al. (1968), working with monkey material, assert that the fibers originate in the orbital cortex and terminate in medial septum. However, Devito and Smith (1964) and Tanaka and Goldman (1976) found that fibers arising in dorsolateral cortex of monkeys reach the septum, and Beritashvili (1971), working with carnivores (cat and $\mathrm{dog}$ ), places the origin in the proreate gyrus. It is interesting to note that the dorsolateral FAC projection to the septum found by Tanaka and Goldman (1976) terminates in the dorsal and dorsomedial regions of septum. These authors further suggest that the dorsolateral prefrontal projection to the dorsal septum arises in the middle third of the principal sulcus.

Nauta (1964) goes so far as to suggest that the FAC is a neocortical extension of limbic mechanisms, subserving the same basic functions. The neuroanatomical data reviewed in the previous two sections does, indeed, indicate strong anatomical relations between these two forebrain systems, and the behavioral literature to be reviewed below further substantiates such a point of view.

To recapitulate, then, it would appear that the frontal cortical areas are an important nodal point in the brain involved in the processing and integration of multimodal sensory and motor information. Furthermore, this integrated input is transmitted to limbic structures via entorhinal hippocampal pathways. In addition, based on the information received, the frontal cortical areas and limbic structures can regulate the channeling of new sensory information and the priming of motor mechanisms in a variety of ways-for example, via connections with extrapyramidal, motor, and premotor centers and interaction with the reticular formation (Auer, 1956; Johnson et al., 1968; Mizuno et al., 1969), and perhaps through a direct action on primary sensory mechanisms (Golden \& Lubar, 1971; Jones, 1969; Powell, Furlong, \& Hatton, 1970).

\section{THE BEHAVIORAL PHYSIOLOGY OF SEPTUM}

Two general hypotheses have evolved during the last three decades dealing with the role of the septal area in the regulation of behavioral processes. One hypothesis extends the view that the septal area regulates emotional and motivational states. The other hypothesis maintains that the septum is an integral part of a neural system which controls response processes. The available literature indicates that both of these hypotheses have some merit. In addition, there would appear to be an anatomical specificity within the septum related to these functions. Lubar and Numan (1973) postulated, on the basis of a large body of data, that the descending projections of lateral septum, ventral septum, and surrounding structures (e.g., stria medullaris) mediate the regulation of motivational states and emotionality. These data will not be elaborated upon here except to mention that this interpretation has subsequently been supported and extended (Albert \& Richmond, 1976, 1977; Brayley \& Albert, 1977; Ross \& Grossman, 1977; Ross, Grossman, \& Grossman, 1977). Lubar and Numan (1973) also postulated that the medial septum and its ascending relations with the hippocampus play a critical role in response regulation. More recent investigations have continued to support this idea, and it is to these data that we now turn.

\section{The Role of the Septum in the Regulation of Response Processes}

Early studies. In 1951, Kaada showed that electrical stimulation of the septal region and subcallosal cortex in cats and monkeys produces both autonomic and somatomotor response inhibition. Incorporating Kaada's findings into a theory of septal function, McCleary $(1961,1966)$ postulated that, since stimulation of the septal region produces an inhibition of somatomotor responses, ablation of this area should produce somatomotor disinhibition, or an inability to appropriately inhibit responses. McCleary (1966) felt that his findings showing impaired passive avoidance learning and enhanced two-way shuttle avoidance acquisition after septal ablation supplied strong support for this theory. However, the fact that septal rats are impaired in the acquisition of a one-way shuttle avoidance response is not congruent with this theory of septal function (Kenyon \& Krieckhaus, 1965a, 1965b). It would seem that large septal lesions effect both emotionality and response regulation (Lubar \& Numan, 1973). Therefore, in avoidance situations, these dual effects interact and make the data difficult to interpret. Nonetheless, there are many behavioral tasks which do require the inhibition of response tendencies without incorporating aversive stimuli into their paradigms, and septal 
animals also show very striking deficits on these tasks. As we shall presently see, the theory as stated by McClearly is too simplistic, and, in addition, there would also appear to exist within the septum an anatomical specificity for what has come to be called septal perseveration.

Anatomical specificity. Current research has indicated that the hippocampal theta response in rat is highly correlated with voluntary movement (Vanderwolf, 1969, 1971, 1975; Whishaw \& Vanderwolf, 1973) and the immobility reflex (Kolb \& Whishaw, 1977; Vanderwoof, Kramis, Gillespie, \& Bland, 1975). Since the medial septum appears to be the pacemaker for hippocampal theta (Petsche et al., 1962, $1965)$ it may very well be the case that the medial portion of the septum plays a strong role in the mediation of response tendencies. In support, Donovick (1968) found that only those ablations confined to the medial septum of the rat disrupted the hippocampal theta response. The important finding, however, is that it was only the thetadisrupting lesions of the medial septum that also disrupted performance on such tasks as spatial alternation and reversal. Lesions elsewhere in the septum that did not disrupt theta did not produce these effects. Similar behavioral effects appear after medial septal ablation in primates (Butters \& Rosvold, 1968). Furthermore, the types of perseverative deficits that occur after septal ablation in rats (e.g., overresponding on operant schedules, lack of spontaneous alternation) appear to be due specifically to damage in the medial septum and diagonal band nuclei (Carey, 1967; Clody \& Carlton, 1969; Kelsey \& Grossman, 1975). In the cat, however, both medial and dorsal portions of the septum have been implicated in these response perseverative impairments (Numan \& Lubar, 1974; Zucker \& McCleary, 1964). Recent studies in rat have indicated that the pathway from medial septum to hippocampus via fornix mediates these response impairments (Ross et al., 1975; Ross \& Grossman, 1975). Further attempts to characterize this pathway have suggested the importance of medial septum-medial fornix-dorsal hippocampus relations (Johnson, Olton, Gage, \& Jenko, 1977). These behavioral findings agree well with the anatomical findings of Siegel and associates discussed earlier (e.g., Siegel et al., 1974), but should probably be interpreted with caution until further experimental evidence becomes available. Further, an analysis of the effects of damage to the dorsomedial sector of the lateral septum might prove interesting (McLennan \& Miller, 1974).

The problem of septal perseveration. Early studies by Ellen and Powell (1962) showed that on a fixed interval schedule, rats with septal lesions attained a higher terminal response rate at the end of the interval than did controls. The work of Harvey and
Hunt (1965) showed increased responding on both fixed interval and continuous reinforcement schedules; and Ellen, Wilson, and Powell (1964) found that septal rats were unable to withhold responding sufficiently long enough to obtain reinforcement on a DRL schedule.

Septally ablated animals also show perseverative behavior during the reversal and alternation of spatial discriminations. For example, septal rats are deficient when compared to normals on the reversal of a spatial discrimination (Schwartzbaum \& Donovick, 1968). Zucker (1965) and Zucker and McCleary (1964) found similar effects in cats, while Butters and Rosvold (1968) found the same in monkeys. Other investigators have found similar effects (Hamilton, Kelsey, \& Grossman, 1970; Thompson \& Langer, 1963). In addition, Clody and Carlton (1969) found a decrease in spontaneous alternation in a $\mathrm{T}$-maze following septal ablation in the rat, and Gittelson and Donovick (1968) found a septally produced deficit on the reversal of a kinesthetic discrimination.

A great deal of interest regarding the effects of septal damage on response processes has been directed toward the DRL task. This is because DRL is a difficult schedule requiring the organism to pace its responses in order to receive reinforcement. The early findings of Ellen, Wilson, and Powell (1964) indicating overresponding by septal rats on DRL schedules have been repeatedly confirmed (Burkett \& Bunnell, 1966; Carey, 1967, 1968; Ellen \& Aitken, 1971; Ellen \& Butter, 1969; Hothersall, Johnson, \& Collen, 1970; MacDougall, Van Hoesen, \& Mitchell, 1969; Pompi, 1974; Thorne, Kieth, \& Topping, 1976).

When responding on a DRL schedule, the septally damaged rat overresponds, being unable to regulate its response rate to the demands of the schedule. It should be pointed out, however, that these data do not indicate a complete lack of response regulation. For example, Carey (1967) has noted that normal and septal rats show the largest number of responses in the 0-2-sec IRT (interresponse time) interval of a DRL 22-sec schedule early in training. As training progresses, the majority of these "response bursts" are eliminated by both septal and normal animals. The normal animal develops a bimodal distribution as training continues, with peaks at (1) relatively short IRTs and (2) the minimal reinforcement interval. Septal animals, however, maintain a unimodal distribution with a peak in the range of relatively short IRTs.

Furthermore, the DRL deficit exhibited by septal rats has been found to be dependent upon the training procedures utilized. Caplan and Stamm (1967) found no impairment in performance on DRL after septal ablation in rats if training proceeded slowly and the length of the DRL interval was 
gradually increased. Ellen and Butter (1969), studying rats, and Numan and Lubar (1974), studying cats, found that septal animals could perform efficiently on a DRL schedule provided that the animals were given external feedback signaling the availability of reinforcement. These authors interpreted the septal impairment in terms of a deficit in proprioceptive processing. That is, the septal animal cannot utilize the response feedback necessary for the formation of effective collateral behavior which, in turn, might be necessary for the development of an accurate temporal discrimination. Support for such a contention is supplied by the work of Laties, Weiss, and Weiss (1969), who have shown that collateral behavior (e.g., wood nibbling) developed by normal rats during DRL acquisition facilitated performance on this task. Ellen and Kelnhofer (1971) have added further support for this interpretation. They found that septal rats were impaired on a counting schedule where the animal was required to respond five times on one lever before switching to another to obtain reinforcement, again indicating inefficient use of response-produced cues. However, a more recent investigation by Braggio and Ellen (1974) has weakened this hypothesis. They found that feedback produced by varying the force required to press a lever ameliorated the septal DRL deficit in rats. While this does not rule out the proprioceptive hypothesis, since pressure cues could have facilitated septal performance, it certainly undermines the hypothesis.

Besides the "proprioceptive hypothesis" presented by Ellen and his associates, there have been many other attempts to explain the perseverative tendencies of septally damaged animals. One line of research has stemmed from the fact that septally damaged animals are overreactive to both positive and negative taste properties of nutrients, and thus perhaps are more highly motivated than are normal animals (Beatty \& Schwartzbaum, 1967; Harvey \& Hunt, 1965). More specifically, in the case of studies using water as a reinforcer, it has been emphasized that septally damaged rats may have an enhanced drive for water consumption, since under normal ad-lib conditions their water intake is significantly greater than that of normal animals (Harvey \& Hunt, 1965; Lubar, Boyce, \& Schaefer, 1968; Wolfe, Lubar, \& Ison, 1967). However, Zucker (1965), working with cats, has indicated that food intake in these animals after septal ablation did not differ from that of normal animals, and Wolfe et al. (1967) have reported increased water consumption in septally ablated rats without a concurrent increase in runway speeds for a water reward. Carey (1967) has controlled for the possible enhancement of thirst in septal rats deprived of water for $23 \mathrm{~h}$ by depriving a normal group for $72 \mathrm{~h}$. Nevertheless, his septal rats still overresponded on a DRL 22 -sec schedule.
In addition, Clody and Carlton (1969) have shown that lesions of the medial septum which produce perseverative tendencies in rats on a variety of tasks do not lead to increased ingestion of sucrose ad lib, and Ross and Grossman (1975) have shown that the ventral connections of the septum selectively mediate overreactivity to the taste qualities of nutrients, while fibers ascending from septum into fornix probably mediate overresponding on operant schedules. Furthermore, the investigations of Carey $(1968,1969)$, Lubar, Schaefer, and Wells (1969), and Paxinos (1975) have shown that increased ingestion of water is due to lesions placed posterior and ventral in the septum, while a large number of studies (Burkett \& Bunnell, 1966; Carey, 1968, 1969; Donovick, 1968; Numan \& Lubar, 1974) have shown that lesions of the anteromedial septum and diagonal band lead to perseverative tendencies. Lastly, impairments in spontaneous alternation following septal ablation cannot be easily explained in terms of lesioninduced motivational changes, since this task does not involve deprivation or obvious rewards for specific responses. Thus, there is both behavioral and anatomical evidence which tends to indicate that septal-produced perseveration is not due to an enhanced motivational state or to a hyperreactivity to the taste qualities of nutrients.

Nevertheless, a number of investigators have recently presented data which has revitalized the motivational hypothesis as an explanation of septallesion-induced behavioral dysfunctions. Henke (1975, 1976) has presented interesting data in an attempt to explain the behavioral dysfunctions of septal rats in terms of enhanced incentive motivation. This point of view has also been supported by the work of DeNoble and Caplan (1977) and Neill, Ross, and Grossman (1974). The problem with these studies, with the exception of the work of Neill et al. (1974), is that the septal lesions were large, and involved all regions of the septum and surrounding structures. Therefore, anatomical specificity for the effects could not be determined. Certainly, the data do suggest that septal lesions modify the motivational disposition of the brain-damaged animal. The problem, however, which is not clearly resolved by these studies, is whether or not these motivational changes are also responsible for the response perseveration noted after septal damage. The work of Kelsey and Grossman (1975), Ross et al. (1975), and Ross and Grossman (1975) suggest that these effects are dissociable. An ascending medial septal influence appears to mediate response perseveration, while a descending septal influence seems to mediate shifts in incentive motivation. However, more research is necessary in order to achieve a satisfactory resolution to this important problem.

Many investigators have attempted to explain septally-produced perseveration in terms of response 
disinhibition (Carey, 1968; Hamilton et al., 1970; MacDougall \& Capobianco, 1976; McCleary, 1966; Ross \& Grossman, 1975). However, an explanation of the behavioral data in terms of disinhibition is not justified. For example, a simple form of the response disinhibition model cannot explain why presentation of an external cue acting as a discriminative stimulus for responding leads to normal inhibition in septal rats (Ellen \& Butter, 1969; Kelsey \& Grossman, 1971) and cats (Numan \& Lubar, 1974). More complex statements of the response disinhibition model of septal function emphasize the point that perseveration will not occur unless a response is dominant. Hence, septal lesions lead to an inability to modify dominant response tendencies, as is the case with deficits in reversal learning. Overresponding on DRL is explained, then, as an inability to modify responses developed during CRF training to the DRL requirements. Both of these suggestions receive negative support. Kelsey and Grossman (1971), using a modified DRL procedure in which CRF pretraining was not necessary, still found a deficit after septal ablation in rats. In addition, septal ablation does not lead to impaired performance when an object discrimination is reversed (Schwartzbaum \& Donovick, 1968; Srebro, 1974; Thomas, 1972). Thus it is quite clear'that most forms of the response inhibition model of septal function cannot adequately explain the findings. What is clear, however, is that septal ablations, specifically those localized in the medial and perhaps dorsal septum, generally impair the organism's ability to regulate its response output when exteroceptive stimuli are absent or largely lacking.

In summary, the available data support the conclusion that the medial septal nucleus, which mediates theta activation in the hippocampus, plays a strong role in response regulatory processes. Destruction of the medial septum seems to be particularly disruptive of response control when salient external cues are not available to guide behavior.

\section{THE BEHAVIORAL PHYSIOLOGY OF FRONTAL ASSOCIATION CORTEX}

One of the first experimental studies dealing with frontal lobe function, and from which much of the current research has stemmed was carried out by Jacobsen in 1936. He observed that monkeys with frontal damage were impaired in delayed response and delayed alternation problems as well as in problems involving sequential acts. His lesioned monkeys showed stereotyped and hyperdistractible behavior along with increased activity and appetite. However, his monkeys performed normally on simple problem boxes and visual discrimination. Based on these results, especially the deficits on delayed response, Jacobsen theorized that frontal lobe injury disturbs the mechanisms of immediate memory.

Stanley and Jaynes (1949) cite extensive evidence which indicates that bilateral removal of the frontal cortical areas in monkeys leads to hypermotility and poor performance on the following tasks: habit reversal problems, seriatum problems (in this task, a sequential and ordered pattern of responding is required), conditional reactions, and delayed response. Simple discriminations were not affected by frontal ablation. Based on these findings, these experimenters proposed a theory of "cortical actinhibition"' as an 'explanation for frontal lobe function. Basically, what this theory proposes is that deficits found after frontal ablation are not due to an impairment in learning ability, but rather an impairment in performance, the brain-damaged animal being unable to inhibit previously learned response sequences.

Furthermore, early behavioral studies in primates have shown that the amount of sensory input is an important factor for the etiology of some of the deficits observed after frontal ablation. Thus, enucleation, darkness, and barbituate administration have been found to ameliorate some of the abnormalities (e.g., hyperactivity, delayed response deficit) found after frontal ablation (Kennard, Spencer, \& Fountain, 1941; Malmo, 1942; Mishkin, Rosvold, \& Pribram, 1953).

Most of the early physiological work dealing with frontal lobe function indicated that the orbital surface of the frontal lobes plays a prominent role in autonomic regulation. Thus, stimulation of the orbital gyrus arrests respiratory movements, may elevate or depress blood pressure depending on locus, and leads to rapid rises in the temperature of the extremities (Stanley \& Jaynes, 1949). These early findings were supported by neuroanatomical and neuronographic studies (Clark, 1948) indicating the close relationship between the orbital surface and the hypothalamus. More recent physiological and anatomical studies have continued to support these conclusions (Girgis, 1971; Kaada, 1960).

Thus, even in the early investigations of frontal lobe function, some segregation of function was envisioned within the frontal cortex: the primate orbital area appeared to be related to autonomic control, while the dorsolateral cortex was related to memory processes and response modulatory functions. In addition, there is some evidence in these early studies for a possible sensory-motor integrative function of FAC.

Contemporary research, with a few exceptions (Beritashvili, 1971; Gross \& Weiskrantz, 1964; Tubbs, 1969), no longer maintains that the FAC is directly involved with memory processes. In some cases, however, certain portions of the FAC have been 
attributed a role in specific types of memory, for example, proprioceptive memory (Goldman \& Rosvold, 1970) and/or spatial memory (Iverson, 1976; Mishkin \& Manning, 1978). The reason that a general memory hypothesis of frontal lobe function has become untenable is partly due to the findings noted above, indicating that barbiturates, enucleation, and darkness can alleviate some of the deficits found after frontal ablation. In addition, the findings indicating a lack of impairment on simple discrimination problems after frontal ablation do not lend support for a frontocortical involvement in memory functions. Furthermore, learning set performance is not disturbed after frontal ablation (Miles, 1964) and long retention intervals are neither necessary nor sufficient to produce impairment in frontally damaged monkeys (Bartus \& Levere, 1977).

Most of the current research has attempted to explain frontal lobe function in terms of response modulatory processes of one kind or another. These views have been advanced for both dorsolateral cortex and orbital cortex, and include various species ranging from rodents to primates, including man (Divac, 1971; Goldman \& Rosvold, 1970; Konorski, 1967; Luria, 1966; Mishkin, 1964; Stamm, 1970; Wagman, 1968; Wegener \& Stamm, 1966).

In the following sections we will attempt a systematic study of some of these findings. Simian data will be analyzed first, followed by data from carnivores, rodents, and man. We will conclude with a discussion of the regulatory role of frontal cortex on sensory mechanisms. [During the preparation of this manuscript a review of the comparative effects of frontal lesions in monkeys, cats, and rats was presented by Markowitsch and Pritzel (1977). Their review is more analytical and less theoretical compared to the present effort.]

\section{Simians}

Damage to the dorsolateral (dL) surface of the primate frontal lobe (most noted in rhesus monkeys, squirrel monkeys, and baboons; chimpanzees appear to be an exception) has repeatedly been found to lead to poor performance on spatial delayed response, spatial reversal, and spatial delayed alternation. The focus for these deficits appears to lie within the middle third of the principal sulcus, and to be highly dependent on the spatial factors inherent in these situations (Butter, 1969; Butters, Pandya, Sanders, \& Dye, 1971; Goldman \& Rosvold, 1970, Goldman, Rosvold, Vest, \& Galkin, 1971; Gross \& Weiskrantz, 1964; Mishkin, 1964; Passingham, 1975). Performance on most simple discrimination tasks presented simultaneously, successively, or differentially is usually not disturbed (Warren \& Akert, 1964). In addition, these ablations, except for a transitional area which lies between the orbital surface and $\mathrm{dL}$, do not produce deficits on similar tasks which do not involve spatial factors (e.g., object reversal, delayed object alternation, go/no-go procedures) or where the importance of spatial factors have been diminished (Butter, 1969; Mishkin, Vest, Waxler, \& Rosvold, 1969; Stamm, 1970).

Based on these findings Goldman and Rosvold (1970) proposed that the role of the $\mathrm{dL}$ cortex in primates may deal with some form of proprioceptive or spatial memory. They conclude that since in the delayed response and delayed alternation tasks there is an absence of salient external cues to guide behavior, monkeys may learn by remembering their own spatially directed responses on the preceding trial (in the case of delayed alternation) or during the baiting phase (for delayed response). In support of this hypothesis, Cianci, Black, Spyropoulos, and Maser (1967) found that monkeys with dorsolateral ablations showed improved performance when tested on an indirect delayed response task (a cue indicates the position of the baited foodwell previous to delay). These results also indicate that a general memory impairment is not involved in the frontal deficit. Buddington, King, and Roberts (1969), using a similar procedure, indicate that dorsolateral damage in the squirrel monkey results in an increased dependence upon external cues for the guidance of behavior during response formation. Furthermore, Stamm (1970), testing rhesus monkeys on three different delayed alternation tasks requiring differential use of kinesthetic information, found that the tasks which relied most strongly on kinesthetic information gave rise to the largest deficits. However, a recent experiment by Mishkin and colleagues (Mishkin, Pohl, and Rosenkilde, 1977) has shown that dorsolateral frontal lesions only lead to a mild impairment in a relatively pure kinesthetic discrimination. These latter results, therefore, favor a spatial impairment rather than a proprioceptive or kinesthetic impairment following dorsolateral frontal removal in monkeys.

While these studies tend to support a spatial specific function for dorsolateral frontal cortex in monkeys, other factors may be involved. For example, Bartus and Levere (1977) present data in favor of an old "frontal hypothesis." They suggest that frontal damage increases susceptibility to the disruptive effects of interference factors. They also suggest that perhaps spatial information is more susceptible to interference in monkeys (with or without frontal removal) and therefore spatial tasks lead to larger deficits following frontal damage than do nonspatial tasks. These ideas, of course, are speculative, but certainly need to be carefully examined in future investigations. I would like to point out, however, that interference can be looked at in terms of feedback information-in this case, irrelevant feedback. Perhaps the problem with frontal monkeys is an in- 
ability to efficiently utilize feedback information, and, therefore, the less salient the existing feedback is (e.g., spatial problems), the more severe the impairment.

Performance on certain operant tasks after frontal ablation also indicates an inability to regulate response patterns. Thus, overresponding on DRL and FI schedules of reinforcement have been reported (Glickstein, Quigley, \& Stebbins, 1964; Pribram, 1959). However, as was the case with septal animals, deficits on DRL, and in addition on delayed response can be mitigated if the delay requirements are progressively, rather than abruptly, increased (Divac \& Warren, 1971; Stamm, 1964).

Based on the totality of these findings, I would like to suggest that while a spatial (or proprioceptive) factor may be necessary to reveal an underlying frontal impairment, it is not actually what is disrupted by the lesion. Rather, it would appear that $\mathrm{dL}$ cortex, primarily in the region of the principal sulcus, is involved in the utilization of feedback information about the consequences of responding. I would like to propose that after $\mathrm{dL}$ ablation primates have difficulty in regulating response patterns when salient exteroceptive stimuli are lacking or are ambiguous. Thus, these surgical preparations cannot centrally integrate feedback from previous responses in order to regulate the formation of new response patterns. This hypothesis predicts that the less external feedback available to guide responding, the greater the observed frontal deficit should be.

Damage to the orbital surface of the frontal lobes leads to poor performance during the reversal of an object discrimination, increases in resistance to extinction and poor differentiation (different responses are related to different stimuli) learning (Butter, 1969; Butters \& Rosvold, 1968; Mishkin, 1964; Mishkin et al., 1969). These deficits are considered to be primarily perseverative in nature, and due to an inability to suppress strong response tendencies both for preferences and aversions (McEnaney \& Butter, 1969; Mishkin, 1964; Mishkin et al., 1969).

However, due to the close anatomical relationship between the dorsolateral and orbital cortex, it is not surprising that there is some overlap in the pattern of deficits observed between the two. In addition, there would appear to be a zone of transition between the two areas (Mishkin \& Manning, 1978; Mishkin, et al., 1969). Thus, Divac, Rosvold, and Szwarcbart (1967) have pointed out that although orbital ablations produce severe deficits in object discrimination reversal, they may also produce impairments on delayed alternation. In addition, Butter (1969) has shown that ablation of the posteromedial sector of the orbital frontal cortex increases resistance to extinction and leads to deficits during the reversal of an object discrimination, while ablation of the lateral orbital surface produces deficient performance on the reversal of a spatial discrimination.

Thus, the two major sectors of the primate FAC appear to play a strong role in response regulatory processes. In addition, the overall spectrum of deficits produced by these two sectors is quite similar to those that occur after septal ablation, and in addition, are related to behavioral patterns seen after hippocampal injury (Douglas, 1967; Kimble, 1968).

\section{Carnivores}

We should recall that gyrus proreus of carnivores is probably homologous to $\mathrm{dL}$ cortex in primates. Most of the work dealing with frontal lobe function in carnivores has stressed the role of the proreal gyrus.

Cats and dogs have repeatedly been found to be deficient on delayed response tests after frontal ablation, specifically after those ablations involving gyrus proreus. However, this deficit is transient, and less severe than that found in primates after $\mathrm{dL}$ damage. Furthermore, dogs appear to learn the response by properly orienting themselves in space during the delay period, while cats have been shown to perform successfully, at least for short delays, without utilizing this pseudosolution (Brutowski, 1965; Divac, 1972; Divac \& Warren, 1971; Konorski \& Lawicka, 1964; Warren, 1964).

Warren (1964) found that large frontal ablations in cats permanently impaired performance on object and spatial reversal problems. The effect is more severe for spatial reversal. Warren, Coutant, and Cornwell (1969) found similar results in the cat when lesions were restricted to gyrus proreus. In addition, the extent of the deficit was positively correlated with the degree of degeneration in nucleus medialis dorsalis of the thalamus. Furthermore, ablation of the pericruciate area, which lies in the vicinity of gyrus proreus, did not lead to such impairments. In addition, Warren et al. (1969) found that cats with proreal ablation were not significantly impaired on a go/no-go object discrimination, and Warren (1964) found the same for a successive object discrimination. Together, these results would indicate, at least for the cat, that after proreal ablation these animals have difficulty in modifying response patterns, the impairments being greater on spatial tasks, and not simply due to a loss in inhibitory control.

Further evidence indicating that carnivores with proreal ablation have difficulty in regulating response patterns, especially when exteroceptive stimuli are lacking is supplied by studies conducted by Numan and Lubar (1974) and Wagman (1968). Wagman (1968) found that proreally damaged cats were deficient when tested on the retention of a $6: 1$ counting schedule learned preoperatively, and that 
the presentation of a cue light indicating when the appropriate count had been reached alleviated the impairment. Numan and Lubar (1974) have shown that proreal cats overrespond on a DRL $40-\mathrm{sec}$ schedule of reinforcement, and that an exteroceptive cue signaling the termination of the delay interval ameliorates the deficit. These authors localized the ventral portion of gyrus proreus as being critical for the production of the DRL impairment.

Teitelbaum (1964) found that proreal and hippocampal ablations impaired the reversal of a tactile discrimination in cats. Teitelbaum suggests that both structures are part of one system, since the effects produced by either lesion alone were remarkably similar, and both structures ablated together did not lead to an additional effect. That gyrus proreus may, in fact, be related to the hippocampus is supported by our previous anatomical discussion.

For carnivores, therefore, frontal damage leads to the same patterns of deficits found in monkeys, albeit less severe. Again, damage to the proreal gyrus (and perhaps specifically its ventral sector) leads to an inability to effectively utilize feedback information for the regulation of response patterns, especially when exteroceptive feedback is absent or largely lacking.

\section{Rodents}

In 1969, Leonard, using anatomical techniques, pointed out that the medial cortex of the rat, anterior to the corpus callosum, may be homologous to the dorsolateral frontal association cortex of primates. Leonard based her analysis on the fact that medial frontal cortex in the rat receives afferents from the thalamic nucleus medialis dorsalis. These findings have recently been substantiated and extended by Krettek and Price (1977a) and Leonard (1972). Prior to these anatomical studies, frontal polar cortex was considered to be homologous to frontal association cortex of primates (Krieg, 1946). Leonard (1969) pointed out, however, that the more lateroposterior portions of the frontal poles are probably part of the rat's motor system. These findings have been substantiated by the electrophysiological studies of Hall and Lindholm (1974). Leonard's work has also suggested, based on thalamocortical projections, that cortex in and around the rhinal sulcus in rats may be homologous to monkey orbital cortex. This region of rat cortex will not be discussed here, we will be concerned with medial cortex which is supposedly homologous to monkey dL cortex. Behavioral effects of sulcal lesions have been studied by Kolb and his colleagues, and the reader is referred to these published reports (Kolb, 1974, 1977; Kolb \& Nonneman, 1975; Kolb et al., 1974).

These anatomical studies encouraged a number of behavioral studies aimed at uncovering functional relations by comparing the behavioral effects of mediodorsal frontal lesions in rats with the behavioral impairments known to occur in cats and monkeys following damage to frontal association cortex (dL). The results, in general, have tended to support the view that medial frontal cortex in rats regulates behavioral functions that are similar to those mediated by homologous cortex in cats (gyrus proreus) and monkeys (dL), although rats with medial frontal damage show impairments that are less severe than those observed in cats (Divac, 1971, 1972; Markowitsch \& Pritzel, 1976; Numan \& Lubar, 1974; Numan et al., 1975; Warren et al., 1969) and monkeys (Butter, 1969; Divac, 1971; Glickstein et al., 1964; Goldman et al., 1971; Kolb et al., 1974; Numan et al., 1975).

Closer scrutiny of the available literature, however, clearly indicates a number of discrepancies. Damage to dorsolateral frontal cortex in monkeys or gyrus proreus in cats has already been shown to lead to impairments on spatial reversal problems and DRL performance. However, the effects of medial frontal lesion in rats on these tasks has not been consistent. Divac (1971) found that rats with damage to medial frontal cortex were impaired during the reversal of a spatial discrimination, while rats receiving damage to the frontal poles were not. This finding has been replicated by Kolb et al. (1974). In contrast, Hannon and Bader (1974) were unable to detect spatial reversal impairments in rats with medial frontal lesions. A study by Buchannon (cited in Hannon \& Bader, 1974) further confuses the picture. He found that rats with medial frontal, lateral frontal, or combined lesions were all impaired and did not differ from each other during reversals of a spatial discrimination. While the reasons for these discrepancies are not clear, procedural and/or anatomical differences could account for these results. A similar analysis results when the literature dealing with DRL performance following medial frontal lesions in rats is assessed. Nonneman et al. (1974), Numan et al. (1975) and Rosenkilde and Divac (1975) detected mild impairments in frontal rats on this task, while Kolb et al. (1974) and Neill (1976) could not uncover such a deficit. Again, procedural and/or anatomical differences could account for these results.

One conclusion that may be reached from these data, however, is that while medial frontal cortex in the rat may mediate some of the functions known to be regulated by frontal association cortex in cats and monkeys, these regulatory processes are poorly developed in the rat and, therefore, may be difficult to detect. This view is harmonious with those presented by Divac (1971), Numan et al. (1975), and Voneida and Royce (1974). The reason for these species differences may, in part, be related to the paucity of frontolimbic connections in rat (Voneida \& Royce, 1974). 


\section{Some Comments on Frontal Lobe Function in Man}

Early studies stressed personality changes after frontal lobotomy in man. These modifications included increased or decreased activity, restlessness and irritability, more vigorous reactions to external stimuli, loss of depth feeling, and increase in egocentrism and extroversion (Freeman \& Watts, 1950; Mettler, 1949). However, as far as performance on general tests of intelligence were concerned, there did not appear to be any drastic changes after frontal lobe damage or disconnection (Freeman \& Watts, 1950; Mettler, 1949). Nevertheless, utilization of past experience or information gained from consequences of action for the planning of future behavior appeared to be disturbed (Freeman \& Watts, 1950). Freeman and Watts conclude that damage to FAC in man impairs constructive act initiation due to inability to visualize what effect ones actions will have upon himself and the environment. On the other hand, Hutton (1943) emphasizes that while normal humans behave on the basis of stimuli which are derived externally and internally, the frontal damaged patient, while capable of responding to stimulation from without, cannot utilize stimuli derived from within. Thus, even in these early studies, emphasis was already developing that indicated that frontal damage in man leads to poor behavioral planning due mainly to a lack of utilization of feedback information relative to the consequences of action.

More recently, Teuber $(1959,1964)$ has shown that damage to the frontal area in man does not produce significant losses on standard intelligence tests, and that performance on the hidden figure test showed them neither better nor worse than subjects with lesions elsewhere in the brain. He found similar results on certain problem solving tasks, including concept formation.

One deficit Teuber does find to be associated with frontal lobe damage concerns the perception of the upright. Frontal ablation in man impairs the ability to set a tilted luminous rod in its upright position when the patient is seated in a darkened room. However, for the effect to occur, the subject's body must also be tilted. These results indicate impaired utilization of proprioceptive and/or vestibular cues, especially as they are related to feedback necessary to localize oneself properly in space.

Furthermore, some evidence has developed to indicate that prefrontal ablation in man leads to an inability to program motor acts based on verbal, visual, or signaled instructions. Thus, Luria (1965, 1966) and Luria and Homskaya (1964) found that frontal patients could not perform sequential tapping tasks to specific rhythms or copy sequences of objects. The subject appears to perseverate with response patterns developed early in the sequence. In most cases, these patients understand the instructions and objectives of the task. These results would tend to indicate that frontal damage in humans can lead to a disruption of the mechanisms involved in the programming of motor acts. Luria $(1965,1966)$ suggests that these disturbances are due to impairments of regulatory mechanisms which enable the outcome of action to be compared with the initial intention.

In agreement with the above results, Milner (1964) found that frontal damage in human subjects caused severe impairments on the Wisconsin Card Sorting Test. This effect did not appear to be due to a general intellectual impairment, since subjects with parietal and temporal damage showed greater losses on IQ tests but performed efficiently on this task. Rather, the impairment appears to be due to an inability to modify response patterns when feedback contingencies relative to the correct response are changed. Furthermore, the subjects are able to verbalize the requirements of the task but, nevertheless, are unable to use this verbalization as a guide to action.

Human subjects with frontal damage also show a similar loss of response flexibility on certain maze tasks (Ackerly, 1964; Konorski, 1967; Milner, 1964). In most cases noted above, the largest behavioral changes occur after destruction of dorsolateral cortex (Konorski, 1967; Luria, 1966; Milner, 1964).

Girgis (1971) presents evidence which indicates that damage to the orbital surface of the frontal lobe in humans leads to changes in emotionality, without greatly impairing the response modulatory characteristics so often seen after dorsolateral damage. Indeed, recent psychosurgical techniques (Girgis, 1971) have shown that restricted lesions limited to orbital cortex greatly improve many depressive states, when other methods (e.g., drugs, shock treatments, psychotherapy) have failed. Furthermore, Girgis emphasizes the importance of two neuronal circuits; one extends from the posteromedial orbital area to the mammillary bodies and the anterior thalamic nuclear groups via the descending columns of the fornix, and the other extends from the more lateral portions of the orbital cortex to the amygdala.

\section{Regulatory Role of Frontal Cortex on Sensory Processes}

The intimate anatomical relations between the FAC and sensory systems, via cortical projections, and FAC connections with the reticular formation, by way of the medial forebrain bundle and the intralaminar and midline nuclei of the thalamus, tend to indicate that the frontal lobes may play an important role in sensory integration and regulation. Indeed, there is some behavioral evidence in support of this view.

Early work by Malmo (1942) showed that delayed 
response impairments in monkeys could be reduced if, during the delay period, the experimental chamber was darkened. These results suggested that frontal ablated animals might be more reactive to novel sensory stimuli, and thus more easily distracted. This assumption has been consistently supported (Bartus \& Levere, 1977; Brutowski, 1965; Grueninger \& Pribram, 1969; Warren \& Akert, 1964). However, while enhanced distraction may contribute to the delayed response impairment, it does not seem to be the main cause of the deficit (Divac, 1969; Warren \& Akert, 1964).

In addition, though frontal ablated animals are not impaired on simple discrimination tasks, more complex sensory discriminations, especially when they are related to differential response patterns are often difficult to solve by the frontal animal. For example, monkeys with prefrontal ablations are inferior when compared to controls on a multiple choice test (Pribram, 1959; Pribram, Ahumada, Hartog, \& Roos, 1964). In this task, the number of objects the animal must discriminate at a given time increases over trials. Similarly, Wegener and Stamm (1966) found that rhesus monkeys have difficulty in learning a successive discrimination when this task is interspersed with other tasks which require response modification. Furthermore, Butler and Eayrs (1969) found that monkeys with lateral frontal ablations were impaired on a conditional reaction. In this task, the animal must shift its response between two stimuli conditional on the occurrence of yet a third stimulus. Butler and Eayrs (1969) hypothesize that frontal animals are unable to regulate response patterns when more than one channel of sensory information must be utilized. This finding is supported by work with humans which has shown an impairment by frontal patients on the category test of the Halstead Battery. In this task, objects must be grouped into categories based on multiple stimulus attributes (Halstead, 1947; Reitan, 1964; Rylander, 1939).

These results indicate, on the whole, that while simple discriminations do not appear to be disturbed after frontal ablation, integrative sensory functions, especially as they are related to response regulatory processes often are disturbed.

A common thread running through many of these studies, and to some extent across species, is that damage to $\mathrm{dL}$ cortex impairs response regulatory functions when salient feedback stimuli are not supplied for the guidance of responding.

\section{A LINK BETWEEN FRONTOCORTICAL AND LIMBIC SYSTEMS: THE HIPPOCAMPUS}

Damage to the hippocampus in a variety of species leads to deficits that are similar to those found after frontal cortical damage and damage to the septum. Thus, damage to the hippocampus increases resistance to extinction, decreases spontaneous alternation, leads to poor performance on spatial reversals and delayed alternation, but does not impair simple discriminations of various types (Dalland, 1970; Douglas, 1967; Jarrard, 1973; Kimble, 1968; Mahut \& Zola, 1973; Rosvold \& Szwarcbart, 1964). Furthermore, deficits on delayed response have also been found after hippocampal ablation (Brutowski, 1965; Douglas, 1967). Hippocampal ablation in rats also leads to poor performance on a DRL schedule of reinforcement, but the critical locus within the hippocampus that mediates this effect has not as yet been clearly determined (Douglas, 1967; Ellen \& Aitken, 1970; Jarrard \& Becker, 1977; Johnson et al., 1977; MacDougall \& Capobianco, 1975; MacDougall et al., 1969). These various deficits found after hippocampal ablation do not appear to be due simply to a disruption of inhibitory mechanisms, since hippocampal animals inhibit responses on no-go trials of a go/no-go single alternation equally well as, if not better than, normal animals (Means, Walker, \& Isaacson, 1970). Furthermore, Olton (1972) presents experimental data suggesting that hippocampal rats show normal response suppression mechanisms, but impaired response shift mechanisms.

Other studies have indicated that normal rats use extra maze cues (when available) in solving various spatial discriminations, and only switch to response cues during overtraining (Means \& Douglas, 1970). However, hippocampal animals use response cues rather than extra maze cues throughout training (Ellen \& Bate, 1970; Means \& Douglas, 1970). Furthermore, Dalland (1970), studying spontaneous alternation behavior in rats, found that hippocampal animals perseverate responses rather than places (response perseveration as contrasted to stimulus perseveration), and Silveira and Kimble (1968) have shown that on the reversal of a brightness discrimination, a task where response cues are irrelevant, hippocampally ablated animals perseverate responses rather than choices to the acquired stimulus. Since hippocampal animals have no problem in the acquisition of most motor responses, and may not show perseveration on tasks that do not require the modification of a prepotent response (Schmaltz \& Isaacson, 1968; Winocur \& Mills, 1969), it would appear that the formation of motor programs is not disturbed after hippocampal ablation. Rather, it appears that once a motor program is formed, it is not modified, thus the animal becomes "stuck" on a particular mode of response, and thus shows response perseveration. This point of view agrees with Olton's (1972) suggestion of an impairment of response shift mechanisms in hippocampal lesioned rats. 
One last point in reference to hippocampal damage should be mentioned. A number of lines of evidence have indicated that hippocampal or fornix damage in rats and monkeys selectively impairs learning of spatial problems, and that the addition of salient exteroceptive cues improves the performance of these brain-damaged animals (DeCastro, 1974; Greene \& Stauff, 1974; Mahut, 1972; Mahut \& Zola, 1973; Stevens \& Cowey, 1972; Winocur \& Bindra, 1976; Winocur \& Breckenridge, 1973; Zola \& Mahut, 1973). Again, therefore, it seems that dorsolateral frontal, septal, fornix, and hippocampal lesions all lead to impairments of response regulation particularly in situations that lack salient exteroceptive stimuli. It may therefore be the case that this system is critical for the programming and regulation of response tendencies in spatial and/or poorly cued situations. This possibility is further supported by the discovery of hippocampal units in rats which selectively respond to spatial factors in the environment (Black, 1975; O'Keefe \& Dostrovsky, 1971; Ranck, 1975).

Most of the experiments discussed so far stressed the similar effects of septal and hippocampal ablations in rats. It is now important to contrast the effects of the two. As was mentioned earlier in our discussion, septal ablation also leads to strong perseverative tendencies. However, in the case of the septal animal, perseveration is not always dependent upon the modification of prepotent response tendencies (Kelsey \& Grossman, 1971; Winocur \& Mills, 1969). In addition, perseveration after septal ablation would appear to be of the stimulus type (place perseveration) rather than the response type found after hippocampal ablation, and septal animals are more prone to utilize exteroceptive cues during maze learning rather than response cues (Clody \& Carlton, 1969; Dalland, 1970, 1974; Ellen \& Bate, 1970; Gomer \& Goldstein, 1974; Sikorszky, Donovik, Burright, \& Chin, 1977; Thomas, 1972). These findings tend to support the proposals indicating an overreliance on external cues and attentional rigidity in septally damaged rats (Bengelloun, Burright, \& Donovick, 1977; Chin, Donovick, \& Burright, 1976; Donovick, Burright, Sikorszky, Stamato, \& MacLaughlin, 1978; Gomer \& Goldstein, 1974).

\section{The Hippocampal Theta Rhythm}

The theta rhythm is a slow $(4-10 \mathrm{~Hz}$, depending on species) sinusoidal waveform which can be recorded from the hippocampus of rodents and carnivores (primate recordings are possible but technically difficult) during various organic states (see Black, 1975; Crowne, Konow, Drake, \& Pribram, 1972; Crowne \& Radcliffe, 1975). The integrity of the hippocampal theta response appears to depend on afferents derived from the medial septum and diagonal band.
Bennett (1971), after reviewing the literature dealing with the behavioral correlates of hippocampal theta, concluded that the occurrence of theta is probably most indicative of orientation towards meaningful environmental stimuli. He suggests that the theta response reflects a comparison between incoming and formerly stored information. However, Vanderwolf $(1969,1971)$ has shown that theta activity precedes and accompanies voluntary types of movement. Vanderwolf's findings have been replicated and extended by numerous investigations (see Black, 1975; Vanderwolf, Kramis, Gillespie, \& Bland, 1975, for reviews). It is my belief that both of these processes (orientation and voluntary movement) are strongly indicative of the roles the hippocampus might play in behavior. Finally, hippocampal theta does not appear to be correlated with the mere reception of reinforcement (Ball \& Gray, 1971; Vanderwolf, 1971).

Gray (1972), in an interesting study, found that septal driving of the hippocampal theta response in rats during acquisition of a locomotor task subsequently increased resistance to extinction. However, if theta-driving was applied during extinction, extinction was facilitated. In addition, the higher the mean theta frequencies elicited, the greater the effects. Moreover, blockage of hippocampal theta during acquisition subsequently reduced resistance to extinction (Gray, Araujo-Silva, \& Quintao, 1972). Gray explains these effects in terms of frustrative nonreward. However, Morris and Black (1978) were unable to uncover a relationship between hippocampal theta and nonreward. If we take into account the data discussed earlier, an alternative explanation of Gray's data is possible. These results could be explained by assuming that the occurrence of hippocampal theta is related to the modification of motor programs, based on the consequences of action. If this were the case, enhancement of theta during acquisition would be indicative of the development of a "strong" motor program which would be greatly resistant to the effects of extinction. On the other hand, enhancement of theta during extinction could be interpreted as facilitating the extinction effect via the rapid formation of a new motor program based on the consequences of action (e.g., absence of reward). In addition, blockage of hippocampal theta during acquisition would lead to the formation of a "weak" motor program, which would be easily disrupted by the effects of extinction. These ideas will be elaborated on shortly.

\section{FORMULATION OF A MODEL OF RESPONSE CONTROL}

To recapitulate, the dorsolateral frontal cortex, the medial septum, and the hippocampus are neuroanatomically related, and have similar afferent and 
efferent connections with various cortical and subcortical centers. In addition, the behavioral deficits observed after destruction of these areas are highly similar and would appear to be related, at least in part, to response regulatory processes. (It should be recalled that aversive paradigms were excluded from the review.) Based on the information discussed in previous sections, it would not seem unreasonable to assume that portions of these three regions are part of a neural system involved with the formulation and modification of motor programs based on feedback information derived from the consequences of action. (It should be noted, at this point, that behavioral models similar to the one about to be proposed have already been published, and many of my ideas have been reinforced by these views; e.g., see Anokhin, 1969; Douglas, 1967; Miller, Galanter, \& Pribram, 1960; Olds, 1969; Luria, 1966; Vinogradova, 1975; Von Holst, 1954).

Since the frontal cortical areas receive (and presumably integrate) sensory and motor information derived from primary and secondary cortical areas, I would like to suggest that motor programs are formulated in the prefrontal cortex. Konorski (1967) and Luria (1966) have reached similar conclusions. Recent neurophysiological data also support this point of view (Niki, 1974a, 1974b, 1974c; Niki \& Watanabe, 1976). Niki's data will be discussed shortly. The formulation of these motor programs is based on the available sensory information, the motivational and emotional state of the organism (perhaps integrated in orbital cortex), and previous experiential factors which dictate the organism's expectations. We might also add that the area lying in the region of the principal sulcus (middle third?) of the dorsolateral frontal cortex would appear to be of particular importance for the assessment of proprioceptive and/or spatiovestibular information for incorporation in the motor program. Once a motor program is formulated, it is transmitted to the hippocampus where it is temporarily stored. The hippocampus can thus be considered the memory mechanism of the system, since it stores the trace of the original motor program [after Von Holst (1954), I will call this trace an efference copy]. Initiation of the motor program occurs when the FAC activates motor mechanisms in the precentral gyrus which, in turn, emits an efferent signal. The efferent signal activates the efference copy in hippocampus to be ready for reafferent feedback (reafferent feedback is used loosely to indicate stimulus changes in the environment and the organism that are the result of responding, i.e., response-dependent stimulus changes). The efferent signal also leads to response initiation, which in turn leads to reafference. This reafferent feedback is transmitted to mesencephalic centers. From these midbrain centers, the reafference (both intero- and exteroceptive) is carried to (1) the cerebral cortex, and (2) the medial septum. From these points, the reafferent information is transmitted to (1) the frontal cortical areas and (2) hippocampus. In hippocampus reafference is compared with the efference copy. If the consequences of responding are congruent with the expectations written into the motor program, the reafference and efferent copy will match and the response sequence will be terminated. However, if these expected consequences of responding are not attained, reafference and efferent copy will not match and the mechanisms involved in formulating a new motor program are set into motion. Under this condition, the frontocortical areas are signaled as to the inappropriateness of the previous response pattern via septohippocampal-entorhinal pathways (Hjorth-Simonsen, 1971; Votaw, 1959, 1960). Based on the stimulus information available, and especially the reafference which was just transmitted to the frontal cortical areas, a new motor program is written and transmitted to hippocampus, and the process begins anew, and continues until efference copy and reafference match, thus terminating the response sequence.

According to this model, therefore, damage to portions of dorsolateral frontal cortex (or homologous cortex in nonprimates), hippocampus, or septum should all lead to similar response regulatory impairments, but for different reasons. Frontal damage impairs the formation of motor programs, hippocampal damage impairs error detection, and septal damage disrupts, at least partially, the transfer of feedback information necessary for response modification. Furthermore, it would be predicted that, as response-independent external feedback (exafference) is decreased or made more ambiguous, larger response regulatory impairments should result. The available literature supports this point and its correlate: the more experimenter-produced feedback supplied to the situation, the less severe the resulting impairments.

From this analysis, it can be seen that destruction of the medial septum should produce perseveration mainly in situations that are largely lacking in response-independent exteroceptive stimuli. In this situation, motor programs are reformulated mainly on the basis of reafference, and since the septum, as indicated by the model, is a critical region mediating the transfer of this information to the hippocampus, response regulation under these conditions should be inferior to that of normals. As we have seen, this, in fact, is the case; septal perseveration occurs when the animal must rely on feedback derived from responding but does not occur in cases where obvious exteroceptive stimuli (exafference) are present (e.g., object reversal, cued 
DRL). In addition, the model would also predict stimulus perseveration in septal animals mainly due to an overreliance on exafference, and an inability to utilize reafference [or even an inability to use response independent exafference when stimulus contingencies are ambiguous or unstable (e.g., see Donovick et al., 1978; Srebro, 1974), as when relevent sources of exafference are varied by the experimenter within or between test sessions].

Destruction of the hippocampus has also been shown to lead to perseveration. However, perseveration in hippocampally ablated animals is of the response type rather than the stimulus type found after septal ablation. This is the case (according to the model), since, in the absence of the hippocampus, motor programs can be written by the frontal cortex, but their modification is impaired because the hippocampus is the region where the multisensory consequences of action are compared against the efference copy. When deviations between expectations and outcomes are detected, hippocampus signals the frontal cortical areas of error and response patterns are reformulated. Destruction of the hippocampus impairs these reformulation processes, and the organism tends to perseverate initial response strategies.

Damage to the dorsolateral surface of the FAC in and around the principal sulcus, gives rise to a loss of response regulation mainly in tasks that depend on spatial information. Our model has stressed the importance of this region for the utilization of proprioceptive and spatiovestibular feedback in the formulation of motor programs. Larger frontal lesions, however, lead to more severe response deficits on spatial and nonspatial problems due to the elimination of appropriate sensory-motor integrative processes in the formulation of response patterns (Mishkin \& Manning, 1978).

This model, of course, is not complete; overlap of function must exist between these structures and other brain regions probably subserve somewhat similar functions, since a total loss of response regulatory mechanisms never occurs after destruction to any of these areas, and in many cases these surgical preparations can reacquire appropriate response control given extended periods of training.

This fronto-cortical-limbic model may also be involved in the differential biasing and/or priming of sensory and motor mechanisms. The transmission of reafferent information via the medial septum to hippocampus, in addition to its role described above, is also conceived to activate neural mechanisms in the hippocampus, which, in turn, transmit information back to the medial and lateral septum. From this point, subcortical sensory mechanisms may be differentially inhibited or excited either directly or indirectly via connections with the reticular formation. Similarly, extrapyramidal structures of the mesencephalon and even spinal motor mechanisms can be tuned by information passed from the septum to the mesencephalon. In this way, the organism can orient itself to anticipated meaningful stimulus input.

In previous sections, I have indicated that the hippocampal theta rhythm is highly correlated with both the orienting response and voluntary movement. In addition, the hippocampal theta response is dependent on pathways running from the medial septum to hippocampus. One can now see why this is the case. Reafferent information traveling from the medial septum to hippocampus is compared with the efference copy of the motor program. It is the neural mechanisms involved in this comparison process which I believe are correlated with hippocampal theta. That is, theta may be a hippocampal electrical pattern initiated just prior to the onset of movement that sets the neuronal networks of the hippocampus to be ready for feedback information. Therefore, the theta response may reflect the activation of neural networks in the hippocampus that are necessary for the comparison process (Henderson \& Greene, 1977; Livesey \& Meyer, 1975; Numan, 1972; Numan et al., 1975; Vinogradova, 1970, 1975). The correlation with voluntary movement is seen to be a secondary consequence of activation of efference copy trace by actual or intended movement (for example, it is known that theta occurs in paralyzed animals; see Black, 1975, for review). In addition, as already noted, the hippocampus may send commands back to the septum for differential priming of sensory and motor centers, leading to the orienting response.

In conclusion, I would like to emphasize that this model is not complete, and, in many ways, is highly speculative. Other neural regions should have been included, since it is clear, both neuroanatomically and functionally, that they play a significant role in this system (e.g., caudate nucleus, Divac, 1972; cerebellum, Harper \& Heath, 1973, and Heath \& Harper, 1974; amygdala, Douglas, 1967). Furthermore, we have not paid attention to neurotransmitter mechanisms in this review, except to mention the cholinergic mediation of the theta responses. Even on this point, it is clear that other transmitter mechanisms are involved, since Vanderwolf and colleagues (Vanderwolf et al., 1975) have shown that there are at least two classes of theta, one which is atropine sensitive and another which is atropine resistant. The mapping of monoamines in the brain also clearly indicates that they must play an active role in frontal and limbic mechanisms (Brownstein, Saavedra, \& Palkovits, 1974; Fuxe, Hökfelt, \& Ungerstedt, 1970; Hokfelt, Fuxe, Johnson, \& Ljungdahl, 1974; Lindvall, Bjorklund, Moore, \& Stenevi, 1974; MacBrown \& 
Goldman, 1977). Future research should further integrate these anatomical and neurochemical systems and facilitate our understanding of the neural and chemical control of behavior.

\section{Some Neurophysiological Support}

I have suggested, based on behavioral and anatomical studies, that motor programs are formulated in frontal cortex. Niki (1974a, 1974b, 1974c; Niki \& Watanabe, 1976) has recently recorded unit responses from monkey dorsolateral frontal cortex, and his findings support this suggestion. Niki found units, within the principal sulcus, which showed activity changes during the delay periods on delayed response-type tasks. One type of unit showed activity changes that were related to the direction of response, and the activity of such units could be used to predict errors. Niki \& Watanabe (1976) concluded that the response to be chosen after the delay might be determined by this type of unit. Additional support comes from Stamm's laboratory (Stamm, 1969; Stamm \& Rosen, 1972). Stamm and Rosen (1972) recorded surface negative steady potential shifts from the dorsolateral prefrontal cortex of monkeys. They found that the negative shifts occurring during the early delay period of a delayed response task correlated well with performance. Further, Stamm (1969) found that disruptive electrical stimulation of the midprincipalis region impaired delayed response performance when applied during this early delay period. Obviously something critical is happening during this time period. While other interpretations are possible, the model presented here suggests that this may be the time that a motor program is being formulated.

Recent neurophysiological studies on the septohippocampal system also lend some support to our model. The model suggests that the medial septum functions to supply afference (more specifically, response correlated reafference) to the hippocampus, and the hippocampus compares this afference against the "memory" of the motor program. In support, Berger, Alger, and Thompson (1976) have found that neural discharges from rabbit hippocampus increase during classical conditioning of the nictitating membrane response. When well established, these neural discharges precede and predict the form of the conditioned response. The neural response therefore models the behavioral response, and could reflect the memory of a motor program.

In a more recent study, Berger and Thompson (1977) made recordings from cell groups in medial and lateral septum during nictitating membrane conditioning in rabbits. This study suggested that the medial septum is not involved in conditioning per se, but rather seems to respond to afference. Segal (1974) and Vinogradova $(1970,1975)$ also present neurophysiological data in support of this conclusion. Vinogradova (1975) also suggests a comparator system in hippocampus which compares the sensory inputs arriving at hippocampus from septal and cortical pathways.

In contrast to the afferent role assigned to medial septum, both Berger and Thompson (1977) and Vinogradova (1975) envision the lateral septum as playing a critical role in the conditioning process. Berger and Thompson found that lateral septal responses were almost identical to hippocampal responses during nictitating membrane conditioning. Vinogradova suggests, on the basis of habituation studies, that hippocampal output feeds back to the lateral septum and modifies its neural activity.

Together, these studies suggest an important relationship between hippocampus and lateral septum. We have not paid great attention to the lateral septum, because selective lesions in this area have been rare. A problem we must deal with now is whether the hippocampus can modulate medial septal activity via input to lateral septum. There is, in fact, some positive support for such a relationship. McLennan and Miller (1974) conducted neurophysiological studies on the rat septohippocampal system. Their results indicated that hippocampal output can influence neural activity in both medial and lateral septum. Interestingly, they suggest that the rhythmic bursting of medial septal cells, which pace the theta rhythm, is dependent upon fimbrial output to lateral septum, which in turn influences the medial septum cells. In relation to this issue, MacDougall and Capobianco (1976) have also postulated a feedback loop from hippocampus to lateral septum that is essential for response regulation.

I have discussed a number of lines of evidence indicating that the medial septum transmits reafference to hippocampus. However, the neurophysiological studies just reviewed implicate all types of afference. It does seem, however, based on the lesion and behavioral data, that the septohippocampal system plays a role in adjusting response output based on response-correlated sensory changes. Perhaps this function is mediated, at least in part, through hippocampal outflow to the lateral septum. The lateral septum could then bias the medial septum to select response correlated afference. This reafference can then be pulsed to hippocampus for comparison with the memory of the motor program. These speculations suggest the need for more selective lesion experiments, particularly between medial and lateral septum, and along the dorsoventral axis of the septum.

\section{Some Comments on Species Differences}

Species similarities, especially across monkeys, cats, and rats have been emphasized in this paper. 
This, of course, is not always appropriate when we are dealing with different lines of evolution, and when species differences clearly exist. However, I have taken the liberty of making certain crossspecies comparisons and generalizations in order to generate the current hypothesis.

In the present review, about $90 \%$ of the relevant septal literature has been derived from rat, much of the literature on hippocampus (particularly dorsal hippocampus) is also derived from rat. Only in relation to frontal cortex could we make clear species comparisons, and species differences were obvious. Generally, the trend was for primates to show the most severe impairments following frontal removal, followed by cat and rat. We postulated, therefore, in relation to anatomical data, that these species differences may be positively correlated with the degree of frontolimbic connectivity (greatest in monkey, least in rat). This analysis brings to mind a comment by Nauta (1964), that frontal cortex may be an extension of the limbic system. Therefore, in the rat, which has a poorly developed and limbic disconnected frontal region, frontal damage produces only mild frontal effects in the classical sense, while limbic damage does produce clear frontal-like impairments. However, a role for frontal cortex clearly begins to develop in cats and is well established in monkeys. Further, the hippocampus has long been known to have memory functions in humans (see Iverson, 1976, for review). However, these memory functions in animals, particularly in rats, have been difficult to determine. The current model does, however, envision the hippocampus of the rat as carrying out memory functions, and this model is compatible with the available literature. Only future research will clearly establish the functional significance of structural changes across species.

\section{REFERENCE NOTES}

1. Taub, E., Teodoru, D., Ellman, S. J., Bloom, R. F., \& Berman, A. J. Deafferentation in monkeys: The function of proprioception in extinction. Paper read at the Psychonomic Society meeting, Chicago, Illinois, October 1965.

2. Taub, E., \& Berman, A. J. The effect of massive somatic deafferentation on behavior and wakefulness in monkeys. Paper presented at the Psychonomic Society meeting, Niagra, Ontario, Canada, October 1964.

3. Krieckhaus, E. E. The mammillary bodies: Their function and anatomical connections. Proceedings of a symposium on The Functional Properties of Hypothalamus, Lublin, Poland, September 16, 1966.

\section{REFERENCES}

ACKERLY, S. S. A case of paranatal bilateral frontal lobe defect observed for thirty years. In J. M. Warren \& K. Akert (Eds.), The frontal granular cortex and behavior. New York: McGrawHill, 1964. Pp. 192-218.

Adams, J. A. Response feedback and learning. Psychological Bulletin, 1968, 70, 486-504.
AKert, K. Comparative anatomy of frontal cortex and thalamofrontal connections. In J. M. Warren \& K. Akert (Eds.), The frontal granular cortex and behavior. New York: McGraw-Hill, 1964. Pp. 372-396.

Albert, D. J., \& Richmond, S. E. Hyperreactivity and aggressiveness following infusion of local anesthetic into the lateral septum and surrounding structures. Behavioral Biology, 1976, 18, 211-226.

Albert, D. J., \& Richmond, S. E. Reactivity and aggression in the rat: Induction by $a$-adrenergic blocking agents injected ventral to anterior septum but not into lateral septum. Journal of Comparative and Physiological Psychology, 1977, 91, 886-896.

ANDY, O. J., \& STEPHAN, H. The septum in the human brain. Journal of Comparative Neurology, 1968, 133, 383-410.

Anokrin, P. K. Cybernetics and the integrative activity of the brain. In M. Cole \& I. Maltzman (Eds.), A handbook of contemporary Soviet psychology. New York: Basic Books, 1969. Pp. 830-856.

AUER, J. Terminal degeneration in the diencephalon after ablation of the frontal cortex in the cat. Journal of Anatomy, 1956, 90 , $30-41$.

BaLl, G. G., \& Gray, J. A. Septal self-stimulation and hippocampal activity. Physiology \& Behavior, 1971, 6, 547-549.

Bartus, R. T., \& LeVERE, T. E. Frontal decortication in rhesus monkeys: A test of the interference hypothesis. Brain Research, 1977, 119, 233-248.

Beatty, W. W., \& Schwartzbaum, J. S. Enhanced reactivity to quinine and saccharine solutions following septal lesions in the rat. Psychonomic Science, 1967, 8, 483-484.

Bengelloun, W. A., Burright, R. G., \& Donovick, P. J. Septal lesions, cue availability, and passive avoidance acquisition by hooded male rats of two ages. Physiology \& Behavior, 1977, 18, 1033-1037.

BENNETT, T. L. Hippocampal theta activity and behavior: A review. Communications in Behavioral Biology, 1971, 6, 37-48.

Berger, T. W., Alger, B. E., \& Thompson, R. F. Neuronal substrate of classical conditioning in the hippocampus. Science, 1976, 192, 483-485.

BERGER, T. W., \& THOMPson, R. F. Limbic system interrelations: Functional division among hippocampal-septal connections. Science, 1977, 197, 587-589.

BERITASHVILI, I. S. Vertebrate memory: Characteristics and origin. New York: Plenum Press, 1971. Pp. 23-37.

Bignall, K. E., \& IMBeRT, M. Polysensory and cortico-cortical projections to frontal lobe of squirrel and rhesus monkeys. Electroencephalography and Clinical Neurophysiology, 1969, 26, 206-215.

BLACK, A. H. Hippocampal electrical activity and behavior. In R. L. Isaacson \& K. H. Pribram (Eds.), The hippocampus (Vol. 2). New York: Plenum Press, 1975.

BLACK, A. H., NADEL, L., \& O'KeEFE, J. Hippocampal function in avoidance learning and punishment. Psychological Bulletin, 1977, 84, 1107-1129.

Braggio, J. T., \& Ellen, P. Differential proprioceptive feedback and DRL performance of normal and septal rats. Journal of Comparative and Physiological Psychology, 1974, 87, 80-90.

Brayley, K. N., \& AlberT, D. J. Suppression of VMH-lesioninduced reactivity and aggressiveness in the rat by stimulation of the lateral septum but not medial septum or cingulate cortex. Journal of Comparative and Physiological Psychology, 1977, 91, 290-299.

Brodal, P. The corticopontine projection in the cat. I. The projection from the proreate gyrus. Journal of Comparative Neurology, 1971, 142, 127-140. (a)

Brodal, P. The corticopontine projection in the cat. II. The projection from the orbital gyrus. Journal of Comparative Neurology, 1971, 142, 141-152. (b)

Brownstein, M., SaAvedra, J. M., \& Palkovits, M. Norepinephrine and dopamine in the limbic system of the rat. Brain Research, 1974, 79, 431-436.

BRUTOWSKI, S. Functions of prefrontal cortex in animals. Physiological Review, 1965, 45, 721-746. 
Buddington, R. W., King, F. A., \& Roberts, L. Analysis of changes in indirect delayed response performance in monkeys with prefrontal lesions. Journal of Comparative and Physiological Psychology, 1969, 68, 147-154.

Burkett, E. E., \& Bunnell, B. N. Septal lesions and the retention of DRL performance in the rat. Journal of Comparative and Physiological Psychology, 1966, 62, 468-471.

Butler, S. R., \& EaYRS, J. T. The role of frontal cortex in the performance of a conditional reaction. Physiology \& Behavior, 1969, 4, 847-852.

ButTer, C. M. Perseveration in extinction and in discrimination reversal tasks following selective frontal ablations in Macaca mulatta. Physiology \& Behavior, 1969, 4, 163-171.

ButTERS, N. \& PANDYA, D. Retention of delayed alternation: Effect of selective lesions of sulcus principalis. Science, 1969, 165, 1271-1273.

Butters, N., Pandya, D., Sanders, K., \& Dye, P. Behavioral deficits in monkeys after selective lesions within the middle third of sulcus principalis. Journal of Comparative and Physiological Psychology, 1971, 76, 8-14.

Butters, N., \& Rosvold, H. E. Effect of septal lesions on resistance to extinction and delayed alternation in monkeys. Journal of Comparative and Physiological Psychology, 1968, 66, 389-395.

CAPLAN, M. An analysis of the effects of septal lesions on negatively reinforced behavior. Behavioral Biology, 1973, 9, 129-167.

Caplan, M., \& Stamm, J. DRL acquisition in rats with septal lesions. Psychonomic Science, 1967, 8, 5-6.

CAREY, R. J. Contrasting effects of increased thirst and septal ablations on DRL responding in rats. Physiology \& Behavior, 1967, 2, 287-290.

CAREY, R. J. A further localization of inhibitory deficits resulting from septal ablation. Physiology \& Behavior, 1968, 3, 645-649.

CAREY, R. J. Contrasting effects of anterior and posterior septal injury on thirst motivated behavior. Physiology \& Behavior, $1969,4,759-764$.

Chavis, D. A., \& Pandy A, D. N. Further observations on corticofrontal connections in the rhesus monkey. Brain Research, 1976, 117, 369-386.

Chin, T., Donovick, P. J., \& Burright, R. G. Septal lesions in rats produced reversal deficits in a simultaneous visual discrimination. Journal of Comparative and Physiological Psychology, 1976, 90, 1133-1143.

Cianci, S. N., Black, P., Spyropoulos, P., \& Maser, J. Differential recovery of delayed response function following prefrontal ablation. Experimental Neurology, 1967, 17, 381-388.

Clark, W. E. L. The connections of the frontal lobes of the brain. Lancet, 1948, 1, 353-356.

Clody, D. E., \& Carlton, P. L. Behavioral effects of lesions of the medial septum of rats. Journal of Comparative and Physiological Psychology, 1969, 67, 344-351.

Crowne, D. P., Konow, A., Drake, K. J., \& Pribram, K. H. Hippocampal electrical activity in the monkey during delayed alternation problems. Electroencephalography and Clinical Neurophysiology, 1972, 33, 567-577.

Crowne, D. P., \& RADCliffe, D. D. Some characteristics and functional relations of the electrical activity of the primate hippocampus and hypothesis of hippocampal function. In R. L. Isaacson \& K. H. Pribram (Eds.), The hippocampus (Vol. 2). New York: Plenum Press, 1975.

DABRowsKa, J. Dissociation of impairment after lateral and medial prefrontal lesions in dogs. Science, 1971, 171, 1037-1038.

Dalland, T. Response and stimulus perseveration in rats with septal and dorsal hippocampal lesions. Journal of Comparative and Physiological Psychology, 1970, 71, 114-118.

Dalland, T. Stimulus perseveration of rats with septal lesions. Physiology \& Behavior, 1974, 12, 1057-1061.

DeCastro, J. M. A selective spatial discrimination deficit after fornicotomy in the rat. Behavioral Biology, 1974, 12, 373-382.

DeNoble, V., \& Caplan, M. Enhanced response acceleration or suppression produced by response-independent food presenta- tions in rats with septal lesions. Journal of Comparative and Physiological Psychology, 1977, 91, 107-119.

Devito, J. L., \& SMith, O. A., JR. Subcortical projections of the prefrontal lobe of the monkey. Journal of Comparative Neurology, 1964, 123, 413-424.

Divac, I. Deiayed response in blind cats before and after prefrontal ablation. Physiology \& Behavior, 1969, 4, 795-799.

Divac, I. Frontal lobe system and spatial reversal in the rat. Neuropsychologia, 1971, 9, 175-183.

Divac, I. Neostriatum and functions of prefrontal cortex. Acta Neurobiologiae Experimentalis, 1972, 32, 461-477.

Divac, I., Rosvold, H. E., \& Szwarcbart, M. K. Behavioral effect of selective ablation of the caudate nucleus. Journal of Comparative and Physiological Psychology, 1967, 63, 184-190.

Divac, I., \& WARREN, J. M. Delayed response by frontal monkeys in the Nencki testing situation. Neuropsychologia, 1971, 9, 209-217.

Donovick, P. J. Effects of localized septal lesions on hippocampal EEG activity and behavior in rats. Journal of Comparative and Physiological Psychology, 1968, 66, 569-578.

Donovick, P. J., Burright, R. G., Sikorszky, R. D., Stamato, N. J., \& MacLaughin, W. W. Cue elimination effects on discrimination behavior of rats with septal lesions. Physiology \& Behavior, 1978, 20, 71-78.

Douglas, R. J. The hippocampus and behavior. Psychological Bulletin, 1967, 67, 416-442.

Ellen, P., \& Aitken, W. C., JR. Absence of overresponding on a DRL schedule by hippocampally-lesioned rats. Physiology \& Behavior, 1970, 5, 489-495.

Ellen, P., \& AITKEN, W. C., JR. Absence of temporal discrimination following septal lesions. Psychonomic Science, 1971, 22, 129-131.

Ellen, P., \& Bate, G. Limbic lesions and cue utilization in the Dashiell Maze. Psychonomic Science, 1970, 1, 47-49.

ELLEN, P., \& ButTER, J. External cue control of DRL performance in rats with septal lesions. Physiology \& Behavior, 1969, 4, 1-6.

Ellen, P., \& KelNhofer, M. Discrimination of response feedback following septal lesions. Psychonomic Science, 1971, 23, 94-96.

Ellen, P., \& Powell, E. W. Effects of septal lesions on behavior generated by positive reinforcement. Experimental Neurology, 1962, 6, 1-11.

Ellen, P., Wilson, A. S., \& Powell, E. W. Septal inhibition and timing behavior in the rat. Experimental Neurology, 1964, 10, 120-132.

EnCABo, H., \& RuARTe, A. C. Non-primary sensory projections of the fronto-orbital cortical area in the cat. Electroencephalography and Clinical Neurophysiology, 1967, 22, 210-219.

EPSTEIN, W. Varieties of perceptual learning. New York: McGrawHill, 1967. Chapter 9.

EvarTs, E. V. Feedback and corollary discharge: A merging of the concepts. Neurosciences Research Program Bulletin, 1971, 9, 86-112.

Fox, C. A. Certain basal telencephalic centers in the cat. Journal of Comparative Neurology, 1940, 72, 1-62.

Freeman, W., \& Watts, J. W. Psychosurgery (2nd ed.). Springfield, Illinois: Thomas, 1950.

FuXE, K. Distribution of monoamine terminals in the CNS. Acta Physiologica Scandinavica, 1965, 64, (Supple 247), 37-85.

FuXE, K., HöKfElt, T., \& UNGERSTEDT, U. Morphological and functional aspects of central monoamine neurons. International Review of Neurobiology, 1970, 13, 93-126.

GiRgIs, M. The orbital surface of the frontal lobe of the brain and mental disorders. Acta Psychiatrica Scandinavica, (Suppl. 222), 1971.

Gittleson, P. L., \& Donovick, P. J. The effects of septal lesions on the learning and reversal of a kinesthetic discrimination. Psychonomic Science, 1968, 13, 137-138.

Glickstein, M., Quigley, W. A., \& Stebbins, W. C. Effect of frontal and parietal lesions on timing behavior in monkeys. Psychonomic Science, 1964, 1, 265-266. 
Golden, G. H., \& LubAR, J. F. Effect of septal and fimbrial stimulation on auditory and visual cortical evoked potentials in the cat. Experimental Neurology, 1971, 30, 389-402.

Goldman, P. S., \& Rosvold, H. E. Localization of function within the dorsolateral prefrontal cortex of the rhesus monkey. Experimental Neurology, 1970, 27, 291-304.

Goldman, P. S., Rosvold, H. E., Vest, B., \& Galkin, T. W. Analysis of the delayed-alternation deficit produced by dorsolateral prefrontal lesions in the rhesus monkey. Journal of Comparative and Physiological Psychology, 1971, 77, 212-220.

Gomer, F. E., \& Goldstein, R. Attentional rigidity during exploratory and simultaneous discrimination behavior in septal lesioned rats. Physiology \& Behavior, 1974, 12, 19-28.

GRAY, J. A. Effects of septal driving of the hippocampal theta rhythm on resistance to extinction. Physiology \& Behavior, 1972, 8, 481-490.

Gray, J. A., Araujo-Silva, M. T., \& Quintao, L. Resistance to extinction after partial reinforcement training with blocking of the hippocampal theta rhythm by septal stimulation. Physiology \& Behavior, 1972, 8, 497-502.

GReEN, J. D., \& ARDUinI, A. A. Hippocampal electrical activity in arousal. Journal of Neurophysiology, 1954, 17, 533-557.

GREene, E., \& STAUFF, C. Behavioral role of hippocampal connections. Experimental Neurology, 1974, 45, 141-160.

GreENWALD, A. G. Sensory feedback mechanisms in performance control: With special reference to the ideo-motor mechanism. Psychological Review, 1970, 77, 73-99.

Gross, C. G., \& Weiskrantz, L. Some changes in behavior produced by lateral frontal lesions in the macaque. In J. M. Warren and $\mathrm{K}$. Akert (Eds.), The frontal granular cortex and behavior. New York: McGraw-Hill, 1964. Pp. 74-101.

Grueninger, W. E., \& Pribram, K. H. Effects of spatial and nonspatial distractors on performance latency of monkeys with prefrontal lesions. Journal of Comparative and Physiological Psychology, 1969, 68, 203-209.

GUILLERY, R. W. Degeneration in the hypothalamic connexions of the albino rat. Journal of Anatomy, 1957, 91, 91-115.

GUILleRY, R. W. Afferent fibers to the dorso-medial thalamic nucleus in the cat. Journal of Anatomy, 1959, 93, 403-419.

HALl, R. D., \& Lindholm, E. P. Organization of motor and somatosensory neocortex in the albino rat. Brain Research, 1974, 66, 23-38.

HALSTEAD, W. C. Brain and intelligence: $A$ quantitative study of the frontal lobes. Chicago: University of Chicago Press, 1947.

Hamilton, L. W., Kelsey, J. E., \& Grossman, S. P. Variations in behavioral inhibition following different septal lesions in rats. Journal of Comparative and Physiological Psychology, 1970, 70, $79-86$.

HANNon, R., \& BADER, A. A comparison of frontal pole, anterior median and caudate nucleus lesions in the rat. Physiology \& Behavior, 1974, 13, 513-521.

HaRper, J. W., \& Heath, R. G. Anatomic connections of the fastigial nucleus to the rostral forebrain in the cat. Experimental Neurology, 1973, 39, 285-292.

HARVEY, J. A., \& HuNT, H. F. Effect of septal lesions on thirst in rats as indicated by water consumption and operant responding for water reward. Journal of Comparative and Physiological Psychology, 1965, 59, 49-56.

HEATH, R. G., \& HARPER, J. W. Ascending projections of the cerebellar fastigial nucleus to the hippocampus, amygdala, and other temporal lobe sites: Evoked potential and histological studies in monkeys and cats. Experimental Neurology, 1974, 45, 268-287.

HELD, R. Plasticity in sensorimotor coordination. In S. J. Freedman (Ed.), The neuropsychology of spatially oriented behavior. Homewood, Ill: Dorsey Press, 1968. Pp. 57-62.

Henderson, J., \& GreEne, E. Behavioral effects of lesions of precommissural and postcommissural fornix. Brain Research Bulletin, 1977, 2, 123-129.

HenKe, P. G. Septal lesions and the extinction of incentivemotivation. Physiology \& Behavior, 1975, 15, 537-542.
Henke, P. G. Septal lesions and aversive nonreward. Physiology \& Behavior, 1976, 17, 483-488.

Huorth-Simonsen, A. Hippocampal efferents to the ipsilateral entorhinal area: An experimental study in the rat. Journal of Comparative Neurology, 1971, 142, 417-438.

Hokfelt, T., FuXe, K., Johansson, O., \& LuUngdahl, A. Pharmacohistochemical evidence of the existence of dopamine nerve terminals in the limbic cortex. European Journal of Pharmacology, 1974, 25, 108-112.

Hothersall, D., Johnson, D. A., \& Collen, A. Fixed-ratio responding following septal lesions in the rat. Journal of Comparative and Physiological Psychology, 1970, 73, 470-476.

Hutron, E. L. Results of prefrontal leucotomy. Lancet, 1943, 6, 362.

IVERSON, S. D. Do hippocampal lesions produce amnesia in animals? International Review of Neurobiology, 1976, 19, 1-49.

JACOBSEN, C. F. Studies of cerebral function in primates: I. The functions of the frontal association areas in monkeys. Comparative Psychology Monograph, 1936, 13, 3-60.

JAMES, W. Principles of psychology. New York: Holt, 1890.

JARrard, L. E. The hippocampus and motivation. Psychological Bulletin, 1973, 79, 1-12.

JARRARD, L. E., \& BECKER, J. T. The effects of selective hippocampal lesions on DRL behavior in rats. Behavioral Biology, 1977, 21, 393-404.

Johnson, C. T., Olton, D. S., Gage, F. H., \& Jenko, P. G. Damage to hippocampus and hippocampal connections: Effects on DRL and spontaneous alternation. Journal of Comparative and Physiological Psychology, 1977, 91, 508-522.

Johnson, T. N., Rosvold, H. E., \& Mishkin, M. Projections from behaviorally defined sectors of the prefrontal cortex to the basal ganglia, septum, and diencephalon of the monkey. Experimental Neurology, 1968, 21, 20-34.

JoNES, E. G. Interrelationships of parieto-temporal and frontal cortex in the rhesus monkey. Brain Research, 1969, 13, 412-415.

KAADA, B. R. Somato-motor, autonomic and electrocorticographic responses to electrical stimulation of "rhinencephalic" and other structures in primate, cat, and dog. Acta Physiologica Scandinavica, 1951, 24 (Suppl. 83).

KAADA, B. R. Cingulate, posterior orbital, anterior insular and temporal pole cortex. In J. Field (Ed.), Handbook of physiology (Vol. 2). Washington, D.C: American Physiological Societv 1960. Pp. 1345-1372.

KELSEY, J. E. Behavioral effects of intraseptal injections of adrenergic drugs in rats. Physiological Psychology, 1976, 4, 433-438.

Kelsey, J. E., \& Grossman, S. P. Nonperseverative disruption of behavioral inhibition following septal lesions in rats. Journal of Comparative and Physiological Psychology, 1971, 75, 302-311.

KelSEY, J. E., \& Grossman, S. P. Influence of central cholinergic pathways on performance on free-operant avoidance and DRL schedules. Pharmacology, Biochemistry \& Behavior, 1975, 3, 1043-1050.

Kennard, M. A., Spencer, S., \& Fountain, G. Hyperactivity in monkeys following lesions of the frontal lobes. Journal of Neurophysiology, 1941, 4, 512-524.

Kenyon, J., \& Krieckhaus, E. E. Decrements in one-way avoidance learning following septal lesions in rats. Psychonomic Science, 1965, 3, 113-114. (a)

KenYon, J., \& KRIECKHAUs, E. E. Enhanced avoidance behavior following septal lesions in the rat as a function of lesion size and spontaneous activity. Journal of Comparative and Physiological Psychology, 1965, 59, 466-468. (b)

Kimble, D. P. The hippocampus and internal inhibition. Psychological Bulletin, 1968, 70, 285-295.

Kimble, G. A., \& Perlmuter, L. C. The problem of volition. Psychological Review, 1970, 77, 361-384.

KolB, B. Dissociation of the effects of lesions of the orbital or medial aspect of the prefrontal cortex of the rat with respect to activity. Behavioral Biology, 1974, 10, 329-343.

KolB, B. Studies on the caudate-putamen and the dorsomedial 
thalamic nucleus of the rat: Implications for mammalian frontallobe functions. Physiology \& Behavior, 1977, 18, 237-244.

Kolb, B., \& Nonneman, A. J. Prefrontal cortex and the regulation of food intake in the rat. Journal of Comparative and Physiological Psychology, 1975, 88, 806-815.

Kolb, B., Nonneman, A. J., \& Singh, R. K. Double dissociation of spatial impairments and perseveration following selective prefrontal lesions in rats. Journal of Comparative and Physiological Psychology, 1974, 87, 772-780.

Kolb, B., \& Whishaw, I. Q. Effects of brain lesions and atropine on hippocampal and neocortical electroencephalograms in the rat. Experimental Neurology, 1977, 56, 1-22.

KONORSKI, J. Integrative activity of the brain. Chicago: University of Chicago Press, 1967.

Konorski, J., \& LAwicka, W. Analysis of errors by prefrontal animals on the delayed-response test. In J. M. Warren \& K. Akert (Eds.), The frontal granular cortex and behavior. New York: McGraw-Hill, 1964. Pp. 271-294.

Kornheiser, A. S. Adaptation to laterally displaced vision: A review. Psychological Bulletin, 1976, 83, 783-816.

Krettek, J. E., \& Price, J. L. The cortical projections of the mediodorsal nucleus and adjacent thalamic nuclei in the rat. Journal of Comparative Neurology, 1977, 171, 157-191. (a)

Krettek, J. E., \& Price, J. L. Projections from the amygdaloid complex to the cerebral cortex and thalamus in the rat and cat. Journal of Comparative Neurology, 1977, 172, 687-722. (b)

KRIEG, W. J. S. Connections of the cerebral cortex: I. The albino rat. A. Topography of the cortical areas. Journal of Comparative Neurology, 1946, 84, 221-227.

Laszlo, J. I., Shamoon, J. S., \& Sanson-Fisher, R. W. Reacquisition and transfer of motor skills with sensory feedback reduction. Journal of Motor Behavior, 1969, 1, 195-209.

LAties, V. C., Weiss, B., \& Weiss, A. B. Further observations on overt "mediating" behavior in the discrimination of time. Journal of the Experimental Analysis of Behavior, 1969, 12, 43-57.

LEONARD, C. M. The prefrontal cortex of the rat. I. Cortical projection of the medio dorsal nucleus. II. Efferent connections. Brain Research, 1969, 12, 321-343.

LEONARD, C. M. The connections of the dorsomedial nuclei. Brain, Behavior and Evolution, 1972, 6, 524-541.

Lewis, P. R., \& Shute, C. C. D. The cholinergic limbic system: Projections to hippocampal formation, medial cortex, nuclei of the ascending cholinergic reticular system, and the subfornical organ and supra-optic crest. Brain, 1967, 90, 521-541.

Lindvall, O. Mesencephalic dopaminergic afferents to the lateral septal nucleus of the rat. Brain Research, 1975, 87, 89-95.

Lindvall, O., Buorkiund, A., Moore, Y., \& Stenevi, U. Mesencephalic dopamine neurons projecting to neocortex. Brain Research, 1974, 81, 325-331.

Livanov, M. N. The application of electronic-computer techniques to the analysis of bioelectric processes in the brain. In $\mathbf{M}$. Cole \& I. Maltzman (Eds.), $A$ handbook of contemporary Soviet psychology. New York: Basic Books, 1969. Pp. 717-734.

Livesey, P. J., \& MeYer, P. Functional differentiation in the dorsal hippocampus with local electrical stimulation during learning in rats. Neuropsychologia, 1975, 13, 431-438.

Lubar, J. F., Boyce, B. A., \& SchaEfer, C. F. Etiology of polydipsia and polyuria in rats with septal lesions. Physiology \& Behavior, 1968, 3, 179-184.

Lubar, J. F., \& Numan, R. Behavioral and physiological studies of septal function and related medial cortical structures. Behavioral Biology, 1973, 8, 1-25.

Lubar, J. F., Schaefer, C. F., \& Wells, D. G. The role of the septal area in the regulation of water intake and associated motivational behavior. New York Academy of Science, 1969, 157, 865-890.

LURIA, A. R. Two kinds of motor perseveration in massive injury of the frontal lobes. Brain, 1965, 88, 1-10.

LurIA, A. R. Higher cortical functions in man. New York: Basic Books, 1966. Chapter 5.

LurIA, A. R., \& HomskaYA, E. O. Disturbance in the regulative role of speech with frontal lobe lesions. In J. M. Warren \& K. Akert (Eds.), The frontal granular cortex and behavior. New York: McGraw-Hill, 1964. Pp. 353-371.

Macadar, O., Roig, J. A., Monti, J. M., \& Budelli, R. The functional relationship between septal and hippocampal unit activity and hippocampal theta rhythm. Physiology \& Behavior, 1970, 5, 1443-1449.

MacBrown, R., \& Goldman, P. S. Catecholamines in neocortex of rhesus monkeys: Regional distribution and ontogenetic development. Brain Research, 1977, 124, 576-580.

MacDougall, J. M., \& Capobianco, S. Dissociation of behavioral inhibition within the fornix system. Physiology \& Behavior, 1976, 17, 755-760.

MacDougall, J. M., Van Hoesen, G. W., \& Mitchell, J. C. Anatomical organization of septal projections in maintenance of DRL behavior in rats. Journal of Comparative and Physiological Psychology, 1969, 68, 568-575.

MAHUT, H. A selective spatial deficit in monkeys after transection of the fornix. Neuropsychologia, 1972, 10, 65-74.

MAHUT, H., \& ZolA, S. M. A non-modality specific impairment in spatial learning after fornix lesions in monkeys. Neuropsychologia, 1973, 11, 255-269.

MaLmo, R. B. Interference factors in delayed response in monkeys after removal of frontal lobes. Journal of Neurophysiology, 1942, 5, 295-308.

Markowitsch, H. J., \& Pritzel, M. Learning and the prefrontal cortex of the cat: Anatomico-behavior interrelations. Physiological Psychology, 1976, 4, 247-261.

Markowitsch, H. J., \& Pritzel, M. Comparative analysis of prefrontal learning functions in rats, cats, and monkeys. Psychological Bulletin, 1977, 84, 817-837.

MCCleary, R. A. Response specificity in the behavioral effects of limbic system lesions in the cat. Journal of Comparative and Physiological Psychology, 1961, 62, 263-269.

MCCleary, R. A. Response modulating function of the limbic system. Initiation and suppression. In E. Stellar \& J. M. Sprague (Eds.), Progress in physiological psychology (Vol. I). New York: Academic Press, 1966. Pp. 210-266.

McEnaney, K. W., \& ButTer, C. M. Perseveration of responding and non-responding in monkeys with orbital frontal ablations. Journal of Comparative and Physiological Psychology, 1969, 68, 558-561.

Mclennan, H., \& Miller, J. J. The hippocampal control of neuronal discharges in the septum of the rat. Journal of Physiology, 1974, 237, 607-624.

Means, L. W., \& Douglas, R. J. Effects of hippocampal lesions on cue utilization in spatial discrimination in rats. Journal of Comparative and Physiological Psychology, 1970, 73, 254-260.

Means, L. W., WAlker, D. W., \& IsaAcson, R. L. Facilitated single-alternation go, no-go acquisition following hippocampectomy in the rat. Journal of Comparative and Physiological Psychology, 1970, 72, 278-285.

Meibach, R. C., \& Siegel, A. Efferent connections of the hippocampal formation in the rat. Brain Research, 1977, 124, 197-224.

Mettler, F. A. (Ed.) (Columbia-Greystone Associates). Selective partial ablation of the frontal cortex. A correlative study of its effects on human psychotic subjects. New York: Hoeber, 1949.

MILES, R. C. Learning by squirrel monkeys with frontal lesions. In J. M. Warren \& K. Akert (Eds.), The frontal granular cortex and behavior. New York: McGraw-Hill, 1964. Pp. 149-167.

Miller, G. A., Galanter, E., \& Pribram, K. H. Plans and the structure of behavior. New York: Holt, Rinehart \& Winston, 1960.

Milner, B. Some effects of frontal lobectomy in man. In J. M. Warren \& K. Akert (Eds.), The frontal granular cortex and behavior. New York: McGraw-Hill, 1964. Pp. 313-334.

Mishkin, M. Perseveration of central sets after frontal lesions in monkeys. In J. M. Warren \& K. Akert (Eds.), The frontal granular cortex and behavior. New York: McGraw-Hill, 1964. Pp. 219-241.

Mishkin, M., \& Manning, F. J. Non-spatial memory after selec- 
tive prefrontal lesions in monkeys. Brain Research, 1978, 143, 313-323.

Misfikin, M., Pohn, W., \& Rosenkilde, C. E. Kinesthetic discrimination after prefrontal lesions in monkeys. Brain Research, 1977, 130, 163-168.

Mishkin, M., Rosvold, H. E., \& Pribram, K. H. Effects of Nembutal in baboons with frontal lesions. Journal of Neurophysiology, 1953, 16, 155-159.

Mishixin, M., Vest, B., WaXler, M., \& Rosvold, H. E. A reexamination of the effects of frontal lesions on object alternation. Neuropsychologia, 1969, 7, 357-363.

Mizuno, N., Clemente, C. D., \& Sauerland, E. K. Fiber projections from rostral basal forebrain structures in the cat. Experimental Neurology, 1969, 25, 220-237.

MorRIs, R. G. M., \& BlACK, A. H. Hippocampal electrical activity and behavior elicited by nonreward. Behavioral Biology, 1978, 22, 524-532.

NaUtA, W. J. H. Hippocampal projections and related neural pathways to the mid-brain in the cat. Brain, 1958, 81, 319-340.

NAUTA, W. J. H. Some efferent connections of the prefrontal cortex in the monkey. In J. M. Warren \& K. Akert (Eds.), The frontal granular cortex and behavior. New York: McGraw-Hill, 1964. Pp. 397-409.

NeILL, D. B. Frontal-striatal control of behavioral inhibition in the rat. Brain Research, 1976, 105, 89-103.

Neill, D. B., Ross, J. F., \& Grossman, S. P. Comparison of the effects of frontal, striatal, and septal lesions in paradigms thought to measure incentive motivation or behavioral inhibition. Physiology \& Behavior, 1974, 13, 297-305.

NIKI, H. Prefrontal unit activity during delayed alternation in the monkey. I. Relation to direction of response. Brain Research, 1974, 68, 185-196. (a)

NIKI, H. Prefrontal unit activity during delayed alternation in the monkey. II. Relation to absolute versus relative direction of response. Brain Research, 1974, 68, 197-204. (b)

NIKI, H. Differential activity of prefrontal units during right and left delayed response trials. Brain Research, 1974, 70, 346-349. (c)

Niki, H., \& Watanabe, M. Prefrontal unit activity and delayed response: Relation to cue location versus direction of response. Brain Research, 1976, 105, 79-88.

Nonneman, A. J., Voigt, J., \& KolB, B. Comparison of behavioral effects of hippocampal and prefrontal cortex lesions in the rat. Journal of Comparative and Physiological Psychology, 1974, 87, 249-260.

Numan, R. The effects of frontal and septal ablation on response regulation in the cat (Doctoral dissertation, University of Tennessee, 1972). Dissertation Abstracts International, 1973, 33 (No. 11), 5545B-5546B. (University Microfilms No. 73-12, 426).

Numan, R., \& LuBAR, J. F. Role of the proreal gyrus and septal area in response modulation in the cat. Neuropsychologia, 1974, 12, 219-234.

Numan, R., Seifert, A. R., \& Lubar, J. F. Effects of mediocortical frontal lesions on DRL performance in the rat. Physiological Psychology, 1975, 3, 390-394.

O'Keefe, J., \& Dostrovsky, J. The hippocampus as a spatial map: Preliminary evidence from unit activity in the freely-moving rat. Brain Research, 1971, 34, 171-175.

OLDS, J. The central nervous system and the reinforcement of behavior. American Psychologist, 1969, 24, 114-132.

Olton, D. S. Behavioral and neuroanatomical differentiation of response-suppression and response-shift mechanisms in the rat. Journal of Comparative and Physiological Psychology, 1972, 78, 450-456.

Olton, D. S., Walker, J. A., \& GAge, F. H. Hippocampal connections and spatial discrimination. Brain Research, 1978, 139, 295-308.

Pandya, D. N., Hallett, M., \& Mukherjee, S. K. Intra- and inter-hemispheric connections of the neocortical auditory system in the rhesus monkey. Brain Research, 1969, 14, 49-65.
PANDYA, D. N., \& Kuypers, H. G. J. M. Cortico-cortical connections in the rhesus monkey. Brain Research, 1969, 13, 13-36.

PANDYA, D. N., \& Vignolo, L. A. Intra- and inter-hemispheric projections of the precentral, premotor and arcuate areas in the rhesus monkey. Brain Research, 1971, 26, 217-233.

Passingham, R. Delayed matching after selective prefrontal lesions in monkeys (Macaca mulatta). Brain Research, 1975, 92, 89-102.

Paxinos, G. The septum: Neural systems involved in eating, drinking, irritability, muricide, copulation, and activity in rats. Journal of Comparative and Physiological Psychology, 1975, 89, 1154-1168.

Petsche, H. Gogolak, G., \& Van Zwieten, P. A. Rhythmicity of septal cell discharges at various levels of reticular excitation. Electroencephalography and Clinical Neurophysiology, 1965, 19, 25-33.

Petsche, H., Stumpf, C. H., \& Gogolak, G. The significance of the rabbit's septum as a relay station between the midbrain and hippocampus. I. The control of hippocampus arousal activity by the septum cells. Electroencephalography and Clinical Neurophysiology, 1962, 14, 202-211.

PoMPI, K. F. Immediate effect of septal area damage on DRL performance in the rat. Journal of Comparative and Physiological Psychology, 1974, 86, 523-530.

Powell, E. W. Septal efferents in the cat. Experimental Neurology, 1966, 14, 328-337.

Powell, E. W., Furlong, L. D., \& Hatton, J. B. Influence of the septum and inferior colliculus on medial geniculate body units. Electroencephalography and Clinical Neurophysiology, 1970, 29, 74-82.

Pribram, K. H. On the neurology of thinking. Behavioral Science, 1959, 4, 265-289.

Pribram, K. H., Ahumada, A., Hartog, J., \& Roos, L. A progress report on the neurological processes disturbed by frontal lesions in primates. In J. M. Warren \& K. Akert (Eds.), The frontal granular cortex and behavior. New York: McGrawHill, 1964. Pp. 28-55.

Raisman, G. The connexions of the septum. Brain, 1966, 89, 317-348.

Raisman, G., Cowan, W. M., \& Powell, T. P. S. The extrinsic afferent, commissural and association fibres of the hippocampus. Brain, 1965, 88, 963-996.

Raisman, G., Cowan, W. M., \& Powell, T. P. S. An experimental analysis of the efferent projection of the hippocampus. Brain, 1966, 89, 83-108.

RANCK, J. B. Behavioral correlates and firing repertoires of neurons in the dorsal hippocampal formation and septum of unrestrained rats. In R. L. Isaacson \& K. H. Pribram (Eds.), The hippocampus (Vol. 2). New York: Plenum Press, 1975.

ReItAN, R. M. Psychological deficits resulting from cerebral lesions in man. In J. M. Warren \& K. Akert (Eds.), The frontal granular cortex and behavior. New York: McGraw-Hill, 1964. Pp. 295-312.

Rose, J. E., \& Woolsey, C. N. The orbito frontal cortex and its connections with the medio dorsal nucleus in rabbit, sheep, and cat. Research Publications of the Association for Nervous and Mental Diseases, 1948, 27, 210-232.

Rosenkilde, C. E., \& Divac, I. DRL performance following anteromedial cortical ablations in rats. Brain Research, 1975, 95, $142-146$.

Ross, J. F., Grossman, L., \& Grossman, S. P. Some behavioral effects of transecting ventral or dorsal fiber connections of the septum in the rat. Journal of Comparative and Physiological Psychology, 1975, 89, 5-18.

Ross, J. F., \& Grossman, S. P. Septal influences on operant responding in the rat. Journal of Comparative and Physiological Psychology, 1975, 89, 523-536.

Ross, J. F., \& Grossman, S. P. Transections of stria medullaris or stria terminalis in the rat: Effects on aversively controlled behavior. Journal of Comparative and Physiological Psychology, 1977, 91, 907-917. 
Rosvold, H. E., \& Szwarcbart, M. K. Neural structures involved in delayed-response performance. In J. M. Warren \& K. Akert (Eds.), The frontal granular cortex and behavior. New York: McGraw-Hill, 1964. Pp. 1-15.

RYLANDER, G. Personality changes after operations on the frontal lobes. London: Oxford University Press, 1939.

Schmaltz, L. W., \& IsaAcson, R. L. Effects of caudate and frontal lesions on retention and relearning of a DRL schedule. Journal of Comparative and Physiological Psychology, 1968, 65, 343-348.

Schwartzbaum, J. S., \& Donovick, P. J. Discrimination reversal and spatial alternation associated with septal and caudate dysfunction in rats. Journal of Comparative and Physiological Psychology, 1968, 65, 83-92.

SEgAL, M. Convergence of sensory input on units in the hippocampal system of the rat. Journal of Comparative and Physiological Psychology, 1974, 87, 91-99.

Siegel, A., Edinger, H., \& OHGAMI, S. The topographical organization of the hippocampal projection to the septal area: A comparative neuroanatomical analysis in the gerbil, rat, rabbit, and cat. Journal of Comparative Neurology, 1974, 157, 359-378.

Siegel, A., \& TAssoni, J. P. Differential efferent projections from the ventral and dorsal hippocampus of the cat. Brain, Behavior and Evolution, 1971, 4, 185-200. (a)

SiEgel, A., \& TAssoni, J. P. Differential efferent projections of the lateral and medial septal nuclei to the hippocampus in the cat. Brain, Behavior and Evolution, 1971, 4, 201-219. (b)

Sikorszky, R. D., Donovick, P. J., Burright, R. G., \& Chin, T. Experiential effects on acquisition and reversal of discrimination tasks by albino rats with septal lesions. Physiology \& Behavior, 1977, 18, 231-236.

Silveira, J. M., \& Kimble, D. P. Brightness discrimination and reversal in hippocampally-lesioned rats. Physiology \& Behavior, 1968, 3, 625-630.

SMALL, W. S. Experimental study of the mental processes of the rat. II. American Journal of Psychology, 1900, 12, 206-236.

Smith, C. M. Acetylcholine release from the cholinergic septohippocampal pathway. Life Sciences, 1974, 14, 2159-2166.

SREBRO, B. Visual cues in successive position reversals: Retention deficits following septal lesions. Physiology \& Behavior, 1974, 12, 639-646.

Sтамм, J. S. Retardataion and facilitation in learning by stimulation of the frontal cortex in monkeys. In J. M. Warren \& $\mathbf{K}$. Akert (Eds.), The frontal granular cortex and behavior. New York: McGraw-Hill, 1964. Pp. 102-125.

STAMm, J. S. Electrical stimulation of monkeys' prefrontal cortex during delayed-response performance. Journal of Comparative and Physiological Psychology, 1969, 67, 535-546.

St Aмm, J. S. Dorsolateral frontal ablations and response processes in monkeys. Journal of Comparative and Physiological Psychology, 1970, 70, 437-447.

Stamm, J. S., \& Rosen, S. C. Cortical steady potential shifts and anodal polarization during delayed response performance. Acta Neurobiologiae Experimentalis, 1972, 32, 193-209.

Stanley, W. C., \& Jaynes, J. The function of the frontal cortex. Psychological Review, 1949, 56, 18-32.

Stevens, R., \& Cowey, A. Enhanced alternation learning in hippocampectomized rats by means of added light cues. Brain Research, 1972, 46, 1-22.

TANAKa, D., \& Goldman, P. S. Silver degeneration and autoradiographic evidence for a projection from the principal sulcus to the septum in the rhesus monkey. Brain Research, 1976, 103, 535-540

Taub, E., \& Berman, A. J. Movement and learning in the absence of sensory feedback. In S. J. Freedman (Ed.), The neuropsychology of spatially oriented behavior. Homewood, Illinois: Dorsey Press, 1968. Pp. 173-192.

Taub, E., Teodoru, D., Ellman, S. J., Bloom, R. F., \& BERMAN, A. J. Deafferentation in monkeys: Extinction of avoidance responses, discrimination and discrimination reversal.
Psychonomic Science, 1966, 4, 323-324.

Teitelbaum, H. A comparison of the effects of orbitofrontal and hippocampal lesions upon discrimination learning and reversal in the cat. Experimental Neurology, 1964, 9, 452-462.

TEUBER, H. L. Some alterations in behavior after cerebral lesions in man. In A. D. Bass (Ed.), Evolution of nervous control from primitive organisms to man. Washington, D.C: ASSA, 1959. Pp. 157-194.

TEUBER, H. L. The riddle of frontal lobe function in man. In J. M. Warren \& K. Akert (Eds.), The frontal granular cortex and behavior. New York: McGraw-Hill, 1964. Pp. 410-444.

Thомаs, J. B. Stimulus perseveration and choice behavior in rats with septal lesions. Journal of Comparative and Physiological Psychology, 1972, 80, 97-105.

Thompson, R., \& LANGer, S. K. Deficits in position reversal learning following lesions of the limbic system. Journal of Comparative and Physiological Psychology, 1963, 56, 987-995.

ThorNe, B. M., KeIth, R., \& Topping, J. S. DRL performance in rats following damage to the septal area, olfactory bulbs, or olfactory tubercle. Physiological Psychology, 1976, 4, 493-497.

TusBs, W. E. Primate frontal lesions and the temporal structures of behavior. Behavioral Science, 1969, 14, 347-356.

VAlverde, F. Studies on the piriform lobe. Cambridge, Massachusetts: Harvard University Press, 1965.

VANDERWOLF, C. H. Hippocampal electrical activity and voluntary movement in the rat. Electroencephalography and Clinical Neurophysiology, 1969, 26, 407-418.

VANDERWOLF, C. H. Limbic-diencephalic mechanisms of voluntary movement. Psychological Review, 1971, 78, 83-113.

VANDERWOLF, C. H. Neocortical and hippocampal activation in relation to behavior: Effects of atropine, eserine, phenothiazines, and amphetamine. Journal of Comparative and Physiological Psychology, 1975, 88, 300-323.

Vanderwolf, C. H., Kramis, R., Gillespie, L. A., \& Bland, B. H. Hippocampal rhythmic slow activity and neocortical lowvoltage fast activity: Relations to behavior. In R. L. Isaacson \& K. H. Pribram (Eds.), The hippocampus (Vol. 2). New York: Plenum Press, 1975.

Van Hoesen, G. W., Pandya, D. N., \& Butters, N. Cortical afferents to the entorhinal cortex of the rhesus monkey. Science, 1972, 175, 1471-1473.

Van Hoesen, G. W., Pandya, D. N., \& Butters, N. Some connections of the entorhinal (area 28) and perirhinal (area 35) cortices of the rhesus monkey. II. Frontal lobe afferents. Brain Research, 1975, 95, 25-38.

Vinogradova, O. S. Registration of information and the limbic system. In G. Horn \& R. A. Hinde (Eds.), Short-term changes in neural activity and behavior. Cambridge: Cambridge University Press, 1970.

VinogRADOVA, O. S. Functional organization of the limbic system in the process of registration of information: Facts and hypotheses. In R. L. Isaacson \& K. H. Pribram (Eds.), The hippocampus (Vol. 2). New York: Plenum Press, 1975.

Voneida, T. J., \& Royce, G. J. Ipsilateral connections of the gyrus proreus in the cat. Brain Research, 1974, 76, 393-400.

VoN Holst, E. Relations between the central nervous system and the peripheral organs. British Journal of Animal Behaviour, 1954, 2, 89-94.

Votaw, C. L. Certain functional and anatomical relations of the cornu ammonis of the macaque monkey. Journal of Comparative Neurology, 1959, 112, 353-382.

Votaw, C. L. Study of septal stimulation and ablation in the macaque monkey. Neurology, 1960, 10, 202-209.

W AGMAN, A. M. I. The effect of frontal lobe lesions upon behavior requiring use of response-produced cues. Journal of Comparative and Physiological Psychology, 1968, 66, 69-76.

Wang, R. Y., \& Aghajanian, G. R. Physiological evidence for habenula as major link between forebrain and midbrain raphe. Science, 1977, 197, 89-91.

WARREN, J. M. The behavior of carnivores and primates with 
lesions in the prefrontal cortex. In J. M. Warren \& K. Akert (Eds.), The frontal granular cortex and behavior. New York: McGraw-Hill, 1964. Pp. 168-191.

W ARREN, J. M., \& AKERT, K. (EDs.), The frontal granular cortex and behavior. New York: McGraw-Hill, 1964.

Warren, J. M., Coutant, L. W., \& Cornwell, P. R. Cortical lesions and response inhibition in cats. Neuropsychologia, 1969, 7, 245-257.

WATSON, J. B. Kinesthetic and organic sensations: Their role in the reactions of the white rat to the maze. Psychological Review Monograph Supplement, 1907, 8(2, Whole No. 33).

Wegener, J. G., \& Stamm, J. S. Behavior flexibility and the frontal lobes. Cortex, 1966, 2, 188-201.

Whishaw, I. Q., \& VANDERWOLF, C. H. Hippocampal EEG and behavior: Changes in amplitude and frequency of RSA (theta rhythm) associated with spontaneous and learned movement patterns in rats and cats. Behavioral Biology, 1973, 8, 461-484.

Winocur, G., \& BiNDRA, D. Effects of additional light cues on passive avoid ance learning and extinction in rats with hippocampal lesions. Physiology \& Behavior, 1976, 17, 915-920.
Winocur, G., \& Breckenridge, C. B. Cue-dependent behavior of hippocampally damaged rats in a complex maze. Journal of Comparative and Physiological Psychology, 1973, 82, 512-522.

Winocur, G., \& Mills, J. A. Hippocampus and septum in response inhibition. Journal of Comparative and Physiological Psychology, 1969, 67, 352-357.

Wolfe, J. W., Lubar, J. F., \& Ison, J. R. Effects of medial cortical lesions on appetitive instrumental conditioning. Physiology \& Behavior, 1967, 2, 239-244.

Zola, S. M., \& MAHUT, H. Paradoxical facilitation of object reversal learning after transection of the fornix in monkeys. Neuropsychologia, 1973, 11, 271-284.

ZuCKER, I. Effect of lesions of the septal-limbic area on the behavior of cats. Journal of Comparative and Physiological Psychology, 1965, 60, 344-352.

Zucker, I., \& McCleary, R. A. Perseveration in septal cats. Psychonomic Science, 1964, 1, 387-388.

(Received for publication January 25, 1978; revision accepted August 15, 1978.) 